\title{
Commitment and states of mind with mood and modality
}

\author{
Alex Silk 1
}

Published online: 31 March 2018

(C) The Author(s) 2018

\begin{abstract}
This paper develops an account of mood selection with attitude predicates in French. I start by examining the "contextual commitment" account of mood developed by Portner and Rubinstein (in: Chereches (ed) Proceedings of SALT 22, CLC Publications, Ithaca, NY, pp 461-487, 2012). A key innovation of Portner and Rubinstein's (P\&R's) account is to treat mood selection as fundamentally depending on a relation between individuals' attitudes and the predicate's modal backgrounds. I raise challenges for P\&R's qualitative analysis of contextual commitment and explanations of mood selection. There are indicative-selecting predicates that are felicitous in contexts where there isn't contextual commitment (in P\&R's sense); and there are subjunctive-selecting predicates that involve no less contextual commitment (in P\&R's sense) than certain indicative-selecting verbs. I develop an alternative account of verbal mood. The general approach, which I call a state-of-mind approach, is to analyze mood in terms of whether the formal relation between the predicate's modal backgrounds and an overall state of mind represents a relation of commitment. Indicative mood in French presupposes that the informational-evaluative state determined by the predicate's modal backgrounds is included in the informational-evaluative state characterizing the event described by the predicate. The account provides an improved explanation of core mood-selection puzzles, including subjunctive-selection with emotive factives, indicative-selection with fiction verbs, indicative-selection with espérer 'hope' versus subjunctive-selection with vouloir 'want', and indicative-selection with commissives versus subjunctive-selection with directives. Subjunctive-selection with modal adjectives is briefly considered. The mood-selection properties of the predicates
\end{abstract}

$\triangle$ Alex Silk

a.silk@bham.ac.uk

1 Department of Philosophy, University of Birmingham, ERI Building, Birmingham B15 2TT, UK 
are derived from the proposed analysis of mood, independently attested features of the predicates' semantics, and general principles of interpretation.

Keywords Mood $\cdot$ Mood selection $\cdot$ Modality $\cdot$ Events $\cdot$ Context-sensitivity $\cdot$ Attitude ascriptions

\section{Introduction}

This paper examines the semantics and pragmatics of verbal mood selection. I focus on the factors affecting the selection of indicative versus subjunctive mood in the complements of attitude verbs and speech-act verbs in French, as in (1)-(2).

(1) Indicative-selecting verb:

a. Alice croit que Blanche est végétarienne.

Alice thinks that Blanche is.IND vegetarian

b. *Alice croit que Blanche soit végétarienne.

Alice thinks that Blanche is.SBJV vegetarian

(2) Subjunctive-selecting verb:

a. *Alice veut que Blanche est végétarienne.

Alice wants that Blanche is.IND vegetarian

b. Alice veut que Blanche soit végétarienne.

Alice wants that Blanche is.SBJV vegetarian

A common approach is to explain the contrast between indicative- versus subjunctiveselecting attitude predicates in terms of a notion of commitment ${ }^{1}$ Attitude ascriptions with indicative complements express judgments of truth, whether according to the attitude subject or the speaker (Bolinger 1968; Noonan 1985; Palmer 1986; Farkas 1992, 2003; Giannakidou 1999; Schlenker 2005; Marques 2009; Siegel 2009; Smirnova 2011; Anand and Hacquard 2013); they describe attitudes that are "prototypically factive" (Portner 1997). Attitude ascriptions with subjunctive complements lack such a commitment (Schlenker 2005; Siegel 2009): they evaluate the complement not by assessing its truth, but by comparing it to a set of alternatives (Farkas 1992, 2003; Giannakidou 1999; Giorgi and Pianesi 1997; Villalta 2000, 2008; Marques 2009; Anand and Hacquard 2013); they describe "non-representational" attitudes (Bolinger 1968), like preferences.

Details of implementation aside, treating mood selection in terms of commitment to the embedded proposition captures many examples well. It captures the selection of the indicative with predicates of acceptance (croire 'believe', savoir 'know') and assertion (dire 'say'), as in (1) and (3). And it captures the selection of the subjunctive with desideratives such as vouloir 'want' and directives (ordonner 'order'), as in (2) and (4).

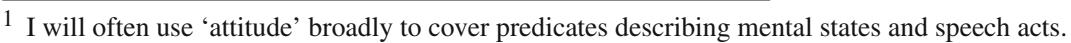


(3) Alice a dit que Blanche est/*soit végétarienne.

Alice said that Blanche is.IND/*is.SBJV vegetarian

(4) Alice a ordonné que Blanche soit/*est végétarienne.

Alice ordered that Blanche is.SBJV/*is.IND vegetarian

But there are well-known puzzle cases. Portner and Rubinstein (2012) provide a crucial advance in systematizing these cases and diagnosing the challenges raised for previous theories. Notably, first, uses of emotive factives ('regret', 'be happy') imply commitment to the embedded proposition, at least by the attitude subject if not also by the speaker. Yet emotive factives contrast with non-emotive factives in typically requiring subjunctive in French, as reflected in (5)-(6).

Alice est heureuse que Blanche soit/*est végétarienne.

Alice is happy that Blanche is.SBJV/*is.IND vegetarian
Alice sait que Blanche est $/ *$ soit
végétarienne.

Alice knows that Blanche is.IND/*is.SBJV vegetarian

On the flip side, fiction verbs ('imagine', 'dream') needn't imply any doxastic commitment, and yet they select indicative, as in (7) with rêver 'dream'.
Alice a rêvé que Blanche était/*fût
végétarienne.

Alice dreamed that Blanche was.IND/*was.SBJV vegetarian

Further, although many desire verbs select subjunctive, as in (2) with vouloir, others, such as espérer 'hope', select indicative:

$$
\text { Alice espère que Blanche est/*soit végétarienne. }
$$

Alice hopes that Blanche is.IND/*is.SBJV vegetarian

And whereas directives select subjunctive, as in (4) with ordonner, commissives select indicative, as in (9) with promettre 'promise'.

$$
\text { Alice promet que Blanche est/*soit végétarienne. }
$$

Alice promises that Blanche is.IND/*is.SBJV vegetarian

Portner and Rubinstein appeal to the contrasts in mood selection among desideratives and between commissives versus directives in arguing against what they call the "proto-standard analysis of mood"-roughly, the view that subjunctive-selecting verbs are precisely those verbs with a comparative semantics. Whatever might distinguish 'hope'/'promise', on the one hand, and 'want'/'order', on the other, it seems unlikely to be that the latter have a semantics involving an evaluative comparison of alternatives while the former do not.

In sum, we have the following mood-selection puzzles to explain (cf. Portner and Rubinstein 2012):

- subjunctive-selection with emotive factives,

- indicative-selection with fiction verbs,

- indicative-selection with espérer versus subjunctive-selection with vouloir,

- indicative-selection with commissives versus subjunctive-selection with directives. 
Why do some attitude verbs implying doxastic commitment select indicative, while others select subjunctive? Why do desire verbs like vouloir select subjunctive, while espérer and fiction verbs select indicative? Why does reporting obligations created with directives require subjunctive, while reporting obligations created with promises requires indicative?

Much progress has been made on these questions. The "commitment-based" approach to mood, as I called it, is in fact a family of approaches. The central aims of this paper are twofold: first, to raise challenges for Portner and Rubinstein's (2012) "contextual commitment" account of mood and diagnosis of mood-selection puzzles such as those above; second, to introduce a novel strategy for exploiting a notion of commitment in an account of verbal mood. The proposed state-of-mind approach provides an improved treatment of the above puzzle cases.

Roadmap: Section 2 explains Portner and Rubinstein's contextual commitment account of mood and its improvements on previous accounts. Section 3 raises empirical and conceptual challenges for Portner and Rubinstein's account. Section 4 develops the alternative state-of-mind account of verbal mood and applies the account to the relevant cases of mood selection in French. Section 5 compares the proposed account to certain others in the literature. Section 6 concludes.

A more detailed overview of the paper is as follows. I start by examining Portner and Rubinstein's ("P\&R's") contextual commitment account of verbal mood (Sect. 2). P\&R's discussion provides a crucial contribution to our understanding of the semantics and pragmatics of mood and modality. A key innovation is to analyze mood selection in terms of a relation between the commitments of the participants in the reported attitude/speech event and the parameters used in the modal evaluation of the clause. Mood selection is explained, not in terms of commitment to the truth of the verb's complement, but in terms of commitment to the verb's modal backgrounds-i.e., to the beliefs, preferences, obligations, etc. which figure in the verb's semantics. Indicativeselecting attitude verbs, on P\&R's view, presuppose that all "relevant individuals are prepared to defend the modal background of the attitude as being reasonable and appropriate" (2012: 462). This view makes room for indicative-selecting verbs such as espérer or promettre with a preference-based comparative semantics. Very roughly: espérer 'hope', unlike vouloir 'want', presupposes that the subject is committed to the relevant desires (and beliefs); and commissives, unlike directives, presuppose that the subject and object are both committed to the obligation-hence indicative-selection with espérer and promettre, and subjunctive-selection with vouloir and ordonner. Or so P\&R argue.

Section 3 argues that P\&R's analysis of contextual commitment and explanations of mood selection are problematic. There are indicative-selecting predicates that are felicitous in contexts where there isn't contextual commitment (in P\&R's sense); and there are subjunctive-selecting predicates that involve no less contextual commitment (in P\&R's sense) than certain indicative-selecting predicates. It isn't commitment to the contents of modal backgrounds-commitment to the reasonableness of the information or priorities - that explains differences in mood selection.

Section 4 develops an alternative commitment-based account of verbal mood. P\&R's strategy is to offer a qualitative notion of commitment and explain mood selection in terms of whether relevant individuals are "committed," in the qualita- 
tively defined sense, to the predicate's modal backgrounds. In contrast, I suggest that we understand mood selection in terms of whether the formal relation between the verb's modal parameters and a relevant state of mind represents a relation of commitment. ${ }^{2}$ Mood is analyzed directly in terms of a relation between a predicate's modal backgrounds and an overall state of mind. I call this general approach a state-of-mind approach to mood.

I propose that indicative mood in French presupposes that the predicate's modal backgrounds are "live" (in a manner to be made precise) from the perspective of the state of mind characterizing the event described by the predicate. States of mind can include doxastic and practical aspects (e.g. beliefs, preferences). Indicative-selecting predicates "presuppose commitment" in the sense of presupposing that the modal state with respect to which the complement is evaluated is implied by the informationalevaluative state characterizing the local attitude/discourse event. These ideas are given a precise formal implementation. Enriching our understanding of states of mind, and refining our treatments of context and content accordingly, helps provide an improved explanation of our mood-selection puzzles. Patterns of mood selection are derived from the proposed account of mood, independently attested features of the verbs' semantics, and general principles of interpretation.

Two remarks on the scope of the paper: First, I focus only on mood marking in French; specifically, on mood marking in complement clauses of attitude verbs; and, more specifically, on cases of mood selection, in which a particular mood is required in the complement clause. There are interesting questions to be asked about crosslinguistic variations in verbal mood, about mood marking in other linguistic contexts (e.g., root clauses, relative clauses, adjuncts), and about interpretive effects of using indicative versus subjunctive with predicates that can embed either mood. I leave it to future research to investigate how the account in this paper may be extended to mood marking in other languages and linguistic environments.

Second, an important contribution of P\&R's discussion is to introduce data with modal adjectives (possible, probable, nécessaire) into the theory of mood. I largely set these adjectives aside. Ongoing contextualism/relativism/expressivism debates and debates about graded modality highlight independently contentious issues regarding how the modal parameters are to be represented in the formal semantics, how the context-sensitivity of epistemic normative/evaluative readings is to be implemented, and how the modal backgrounds are determined as a function of context. ${ }^{3}$ Focusing on attitude and speech-act verbs, whose modal backgrounds are lexically specified as a function of individual arguments, allows us to abstract away from confounding issues regarding the context-sensitivity and modal backgrounds of P\&R's modal adjectives. The verbs under consideration highlight the central mood-selection issues and the core challenges for previous theories such as P\&R's. I return to modal adjectives in Sect. 4.4.

2 Thanks to a referee for suggesting this way of situating the account in comparison to P\&R's.

3 See e.g. Stephenson (2007), Yalcin (2007), von Fintel and Gillies (2010), Lassiter (2011, 2015), Kratzer (2012), MacFarlane (2014), Silk (2016, 2017, 2018), and Swanson (2016). 


\section{Portner and Rubinstein's contextual commitment account of mood}

This section examines Portner and Rubinstein's (P\&R's) contextual commitment account of verbal mood. I begin with relevant formal background.

Following much semantically-oriented work on mood, P\&R use a broadly Kratzerian $(1981,1991)$ framework in giving the semantics of attitude predicates. Modal expressions are interpreted with respect to two modal backgrounds, or functions from worlds to sets of propositions. Given an evaluation world $w$, these modal backgrounds determine a modal base $f(w)$ that represents a body of information, and an ordering source $g(w)$ that represents a body of priorities (norms, values, goals, etc.). What modal backgrounds are supplied may depend on context, as with many modal auxiliaries, or be determined by the lexical semantics, as with attitude verbs. For instance, a doxastic attitude verb such as croire 'believe' takes a modal base that represents the subject's beliefs.

Whereas modal bases must be consistent and include the evaluation world, i.e. $\forall w: w \in \bigcap f(w)$, ordering sources needn't have either of these properties. An ordering source $g(w)$ can be used to generate a preorder on the set of worlds in the modal base $\left(\bigcap f(w), \lesssim_{g(w)}\right)$ or on a set of alternative propositions $\left(C, \leq_{g(w)}\right) .{ }^{4}$ What P\&R call the "proto-standard analysis of mood" treats subjunctive-selecting predicates as those which take a non-empty ordering source, leading to a comparative semanticsas reflected in the first-pass semantics for vouloir 'want' in (10), in contrast to the semantics for croire 'believe' in (11).

$$
\begin{aligned}
& \llbracket x \text { vouloir } p \rrbracket^{w}=1 \text { iff } p<D E S_{x, w} \neg p \\
& \llbracket x \text { croire } p \rrbracket^{w}=1 \text { iff } \bigcap D O X_{x, w} \subseteq p
\end{aligned}
$$

As $\mathrm{P} \& \mathrm{R}$ observe, indicative-taking verbs such as espérer 'hope' and promettre 'promise' pose a challenge for such a view. Espérer would presumably be like vouloir 'want' in taking a bouletic ordering source DES that represents the subject's desires; and promettre would presumably be like ordonner 'order' in taking a deontic ordering source $O B L$ that represents the subject's obligations. A defender of the proto-standard theory might respond by treating $D E S / O B L$ as modal bases with indicative-taking verbs, presupposing that the relevant desires/obligations are consistent. This would lead to a non-comparative semantics like (12) for espérer. Yet saying this undermines the predictiveness of the account. As P\&R note, any non-comparative semantics can be reformulated in a comparative way, as in (13) for croire, letting $D O X_{x, w}$ be a premise

\footnotetext{
4 The preorder on worlds $\lesssim g(w)$ can be generated from the premise set $g(w)$ in the usual way: for any worlds $u, v, u \lesssim_{g(w)} v:=\forall p \in g(w): v \in p \Rightarrow u \in p$. How the order on propositions is generated won't be important for our purposes (cf. Kratzer 1991, 2012; Lassiter 2015). One might read ' $p<g(w) \neg p$ ' as saying that for every $\neg p$-world in $\bigcap f(w)$, there is a $p$-world in $\bigcap f(w)$ that satisfies a (possibly improper) superset of propositions in $g(w)$, and not vice versa. With attitude verbs, the modal backgrounds may take an individual argument in addition to a world argument. I often include only a world argument when talking about modal bases and ordering sources in general. For ease of exposition I sometimes use 'modal base'/'ordering source' for the modal background $h$, sometimes for the set of propositions $h(w)$, and, with modal bases, sometimes for the set of worlds $\bigcap h(w)$ in which these propositions are true; context should disambiguate.
} 
set that represents the ideal of approximating $x$ 's doxastic state of mind (cf. Bittner 2011).

$$
\begin{aligned}
& \llbracket x \text { espérer } p \rrbracket^{w}=1 \text { iff } \bigcap D E S_{x, w} \subseteq p \\
& \llbracket x \text { croire } p \rrbracket^{w}=1 \text { iff } p<D O X_{x, w} \neg p
\end{aligned}
$$

(cf. Portner and Rubinstein 2012: 468-469)

Indeed, minimality semantics are commonplace in literatures on belief change and updating (cf. Makinson 1993). Absent an independent account of what type of modal background a body of desires, beliefs, obligations, etc. provides in different cases, appealing to a comparative semantics is insufficiently explanatory.

To avoid this problem P\&R treat mood selection in terms of commitment to the modal backgrounds associated with the attitude predicate. $\mathrm{P} \& \mathrm{R}$ define the relevant notion of commitment as follows, drawing on Rubinstein (2012) (see also Rubinstein 2014; Portner and Rubinstein 2016). (P\&R follow Hacquard 2006 in treating modal backgrounds as relativized to events, as opposed to worlds; more on this in Sect. 4.)

\section{Commitment to modal backgrounds ( $P \& R)$}

"An individual $a$ is COMMITTED TO a modal background $h$ in event $e$ iff $a$ is disposed/prepared in $e$ to argue for $h(e)$ in a conversationally appropriate way (e.g., by arguing that it is rational/proper/sensible/wise) in any relevant conversation $c . "$

(Portner and Rubinstein 2012: ex. (40))

One is "committed to a modal background" (modal base, ordering source), in P\&R's sense, iff one treats its content (2012: 475)—-the information, preferences, etc.—as "reasonable" and one is "willing to defend it" (2012: 471). What distinguishes indicative from subjunctive mood, on P\&R's account, is a presupposition of contextual commitment: Indicative presupposes that every individual argument of the predicate is committed (in the sense of (14)) to every modal background associated with the predicate. ${ }^{5}$ Subjunctive lacks such a presupposition; it has no semantic effect.

$\mathrm{P} \& \mathrm{R}$ argue that the defined qualitative notion of commitment explains the contrasting mood-selection properties of otherwise notionally similar predicates: in each case, $\mathrm{P} \& \mathrm{R}$ 's diagnosis is that the indicative-selecting predicate presupposes contextual commitment, and the analogous subjunctive-selecting predicate does not. Take espérer 'hope' and vouloir 'want'. P\&R note that the speaker in (15) can report the king's desire using 'want' but not 'hope'. (For expository purposes I sometimes use the English expression for the item crosslinguistically. $)^{6}$

[Context: The king is being bothered by an uppity bishop and makes his annoyance known to some knights. These knights go and kill the bishop, and

\footnotetext{
5 Note that what P\&R's commitment condition requires is (i) a disposition to argue (not necessarily an actual argument), (ii) that the disposition holds in $e$ (in the reported event described by the predicate, not necessarily in the speech/evaluation event), and (iii) that this disposition in $e$ is to argue in any relevant $c$ (cf. Portner and Rubinstein 2012: 478). We will return to these components.

6 I assume with P\&R, following Iatridou (2000), that conditional mood is a form of the indicative.
} 
when the king hears about it, he is angry because it makes him look bad with the church. The knights respond with (a) or (b).]

a. Mais vous vouliez qu'il soit tué! but you wanted that he be.SBJV killed 'But you wanted him to be killed!'

b. ?? Mais vous espériez qu'il serait/est tué! but you hoped that he be.COND.IND/is.IND killed

?? 'But you hoped for him to be killed!'

(Portner and Rubinstein 2012: ex. (25))

Contextual commitment provides a diagnosis: The 'hope'-ascription presupposes that the subject (=the king) is committed to his desire for the bishop to be killed. Using 'hope' is anomalous insofar as the king isn't prepared to defend this desire as reasonable in the conversation. By using 'want' the speaker can report the king's desire without implying that the king is committed to it. So, since espérer 'hope' presupposes contextual commitment, it selects indicative; since vouloir 'want' doesn't presuppose contextual commitment, it selects subjunctive.

Similarly, P\&R claim that although 'promise' and 'order' both report creations of obligations, they differ with respect to contextual commitment. With promising, "the promiser and promisee must see the thing promised as preferable"; yet with ordering, "the person ordered need not think what they are ordered to do is preferable" (2012: 473). Consider (16)-(17).

Marie a promis à Bill qu'elle amènerait le dessert à la fête. Marie has promised to Bill that she bring.COND.IND the dessert to the party 'Mary promised Bill to bring dessert to the party.'

Marie a demandé à Bill qu'il amène le dessert à la fête.

Marie has demanded to Bill that he bring.SBJV the dessert to the party

'Mary ordered Bill to bring dessert to the party.'

(Portner and Rubinstein 2012: exs. (29)-(30))

In promising Bill that she will bring dessert, Mary "proposes to bind [herself] with a priority, and [Bill] has no grounds for disputing this" (2012: 473). Hence in promise reports such as (16) there is contextual commitment to the priority-both subject and object are prepared to defend it-and promettre selects indicative. By contrast, if Mary orders Bill to bring dessert, "the priority [of Bill's bringing dessert] may be controversial, ... and [Bill] may dispute it" (2012: 473). Hence in order reports such as (17) there needn't be contextual commitment to the priority-the object needn't be prepared to defend it-and ordonner selects subjunctive.

(This last move is too quick: What about uses of ordonner where the object judges that what is ordered of him/her is appropriate? Or uses of vouloir where the subject is prepared to defend her desires as reasonable? P\&R explain the fact that indicative still cannot be used in such contexts by positing that, because the contextual commitment condition isn't in general satisfied, the lexical items have become grammatically associated with subjunctive (2012: 481). We will return to this issue throughout the following sections.) 


\section{Challenges}

This section raises challenges for P\&R's contextual commitment account of mood. For clarity let's use 'commitment ${ }_{P R}$ ' for commitment in P\&R's sense, as analyzed in (14): $a$ is committed co $_{P R}$ to a modal background $h$ in $e$ iff for all propositions $p \in h(e), a$ is prepared to defend that $p$ is "reasonable" or "rational/proper/sensible/wise" in any relevant conversation. Likewise let's say that $a$ is $\operatorname{committed}_{P R}$ to a given proposition $p$ in $e$ iff $a$ is prepared to defend that $p$ is reasonable, etc. in any relevant conversation (i.e. iff for some $h$ such that $p \in h(e), a$ is $\operatorname{committed}_{P R}$ to $h$ in $e$, as for the trivial case where $h(e)=\{p\})$. The general concern is that this intuitive notion of commitment isn't fit to explain the full range of data. Contextual commitment $P R$ fails to delineate the classes of indicative- and subjunctive-selecting predicates.

\subsection{Desideratives and doxastics}

P\&R offer the following additional contrasts between 'hope' and 'want':

(18) a. He doesn't fully realize it yet, but Ron wants to date Hermione.

b. ?? He doesn't fully realize it yet, but Ron hopes to date Hermione.

a. I want to marry Alice and I want to marry Sue.

b. ?? I hope to marry Alice and I hope to marry Sue.

(Portner and Rubinstein 2012: exs. (26)-(27))

P\&R cite (18)-(19) as evidence against accounts which claim that what distinguishes 'hope' from 'want' is that 'hope' requires that the subject believe the complement to be possible: using 'hope' in $(18 b) /(19 b)$ is infelicitous even though the subject believes the complement is possible. Instead P\&R claim that using 'hope' is infelicitous because the subject isn't committed ${ }_{P R}$ to the relevant preferences: (18b) is infelicitous since "commitment to a preference, in the relevant sense, requires being aware of it," and (19b) is infelicitous "since it is impossible to be committed to inconsistent preferences" (2012: 471-472). These explanations are problematic.

Consider (19). Pace P\&R, it is possible to be committed, in the sense of (14), to conflicting preferences. Commitment $P R$ to conflicting preferences simply requires that the subject be prepared to defend each preference as "reasonable and appropriate" (2012: 462) in any relevant conversation. One can imagine our torn lover in (19) saying, "It would be reasonable for me to marry Alice. We have such deep conversations, and we've been through so much together. Yet it's Sue that I can't stop thinking about. It would be reasonable for me to marry her, too. I adore each of them, and I'm sure I would be happy either way. What to do!" Such a state of mind might incur a practical conflict, but it isn't impossible.

Note the contrast with belief. Even if it is possible to have inconsistent beliefs, it is impossible to have inconsistent beliefs which are all correct, i.e. true (Stalnaker 1984). Correctness for preferences isn't truth but desirability; roughly put, a preference is correct if its content is genuinely valuable or worth satisfying (e.g., Gibbard 1990, 2005; Piller 2006). As dilemmas with incomparable preferences (values, norms, 
etc.) highlight, accepting inconsistent priorities might not only be possible but correct (Gowans 1987; Sinnott-Armstrong 1988; Goble 2013).

P\&R's treatment of (18b) raises problems for their treatment of croire 'believe'. Croire is like espérer in selecting indicative. However, examples analogous to (18b) with 'believe' can be felicitous. (20) reports Bert's implicit beliefs about women. ${ }^{7}$

(20) [Context: Bert consciously judges that women are equally capable as men in the workplace, but he is also implicitly biased against women. A psychologist examining Bert's results in an implicit attitudes experiment says:]

Bert doesn't fully realize it yet, but he thinks that women are less capable than men in the workplace, and that their proper place is in the home.

Reporting Bert's implicit attitudes with 'believe' is felicitous even though Bert isn't aware of them and isn't disposed to defend them - indeed, even though Bert is disposed to sincerely deny them. It is interesting that in Williamson's classic discussions of failures of transparency, his paradigm cases are precisely belief and hope:

$[\mathrm{O}]$ ne is sometimes in no position to know whether one is in the mental state of hoping $p$. I believe that I do not hope for a particular result to a match; I am conscious of nothing but indifference; then my disappointment at one outcome reveals my hope for another... [Transparency] fails for the state of believing $p$, for the difference between believing $p$ and merely fancying $p$ depends in part on one's dispositions to practical reasoning and action manifested only in counterfactual circumstances, and one is not always in a position to know what those dispositions are. (Williamson 2000: 24)

Williamson's hoper isn't prepared to defend the preferability of such-and-such team's winning in any relevant conversation; for all he would say, he is indifferent. Examples like (18b) with 'hope' improve insofar as context makes clear one's grounds for attributing the implicit attitudes to the subject, as in (21)-(22).

(21) TW hoped the Giants would win, but he didn't fully realize it at the time.

(22) [Context: Same as (20)]

Bert doesn't fully realize it yet, but he hopes his wife doesn't end up getting the job, so that she can stay home with the kids.

P\&R might respond that cases of implicit attitudes, failures of transparency, etc. are exceptional enough so as to be ignored by the language faculty. At minimum, the felicity of the sorts of examples in (20)-(22) challenges the explanatoriness of accounting for indicative-selection in terms of commitment $t_{P R}$ to modal backgrounds (more on which below).

P\&R distinguish 'want' and 'hope' partly in terms of the kinds of preferences they describe. 'Want' describes "visceral," "glandular" preferences; 'hope' describes

7 Cf.: "What is happening here, I think, is that he's [my husband is] revealing what he doesn't realize he believes: that I'm only doing what I should be doing anyway, whereas he is doing something special, something that isn't really his job to do." (www.swistle.com/2006/09). 
“intellectual” preferences (2012: 471). Since “one cannot help one's glandular-buletic preferences..., there's no guarantee they will be defensible" (2012: 479)-hence subjunctive-selection with vouloir. These remarks are in tension with P\&R's account of indicative-selection with croire. Belief is also often not up to us. Consider your present occurrent belief that you are reading a paper. Here is Plantinga:

You ask me what I had for breakfast: I find myself believing that what I had for breakfast was a grapefruit. I am appeared to redly; I find myself with the belief that I am perceiving something red... In each of these cases (as in general), I have little or no direct or conscious control. (Plantinga 1993: 177)

Debates in philosophy and psychology have concerned whether any beliefs are voluntary (Alston 1988; Bennett 1990).

P\&R might reply that even if we "cannot help" having many of our beliefs, we are still typically prepared to defend them. Examples such as (23)-(24) are perhaps the exception rather than the rule.

[Context: Same as (20)]

Bert thinks that women are less capable than men in the workplace, but he would deny it if you asked him.

Fideist: I believe that God exists. I have no arguments; indeed my belief may even be contrary to reason. But I can't help but believe, any more than you can help believing that you are reading this example.

Likewise for (25) with 'hope'.

TW hopes the Giants will win, but he would deny it if you asked him.

The exceptionality of such examples might warrant treating croire and espérer as lexically associated with indicative, and hence as licensing indicative even when the commitment $_{P R}$ presupposition isn't satisfied. Although $\mathrm{P} \& \mathrm{R}$ speculate that grammaticalized mood may only occur with subjunctive-selecting predicates - as mentioned in Sect. 2 with vouloir and ordonner (2012: 481-482)_perhaps P\&R might treat croire and espérer as cases of grammaticalized indicative.

Appealing to grammaticalization in these ways for the paradigm indicativeselecting and subjunctive-selecting predicates threatens the explanatory and predictive power of P\&R's commitment-based semantic definition of mood. It is incorrect that the contextual commitment $_{P R}$ presupposition "is guaranteed to be satisfied [with croire], in virtue of the nature of believing events," or that the presupposition "would not typically be satisfied [with vouloir], in virtue of the nature of wanting events" (2012: 477). We are typically prepared to defend our preferences as well as our beliefs; conversely, we sometimes have beliefs as well as preferences which we wouldn't defend. Given P\&R's contextual commitment account, one could just as easily have speculated (e.g.) that croire would be lexically associated with subjunctive. To parrot P\&R's remark quoted above (p. 479), “One cannot help one's beliefs, and because of this, there's no guarantee they will be defensible. Nevertheless, we may want to describe them, so a verb like 'believe' is essential." I don't deny that some degree of grammaticalization 
is involved in mood selection, or that grammaticalization can be arbitrary (cf. Palmer 1977: 21). The question is whether specific choices in matters of mood selection are best explained in terms of contextual commitment $P R$.

P\&R's treatment of espérer versus vouloir raises questions about mood selection with emotive factives (e.g., regretter 'regret', être heureux 'be happy'). Uses of emotive factives imply that the subject believes the complement, and thus presumably that the subject is committed ${ }_{P R}$ to the modal base that entails it. Further there doesn't seem to be anything necessarily "visceral" or "glandular" about the relevant preferences. The attitudes described by emotive factives don't in general seem any less "intellectual" than those described by espérer 'hope'. Yet emotive factives generally select subjunctive in French. It isn't obvious how to explain this simply in terms of dispositions to defend modal backgrounds.

\subsection{Commissives and directives}

$\mathrm{P} \& \mathrm{R}$ explain the contrasting mood-selection properties of promettre 'promise' and ordonner 'order' in terms of whether the verb's object need be committed ${ }_{P R}$ to the deontic ordering source: whereas both the promisor and the promisee must be committed $_{P R}$ to what is promised, the object of an order needn't be committed PR $_{P R}$ to what is ordered; hence promettre selects indicative, and ordonner selects subjunctive.

Start with P\&R's account of promising. P\&R follow Searle in treating it as a necessary condition on promising that the promisee view what is promised as preferable; in order for X to promise $Y$ that Z, Y must find it preferable that Z (2012: 473). Note that in order for the contextual commitment presupposition to be satisfied, it isn't sufficient that the promisor believe that the promisee would view what is promised as preferable; the promisee, as the object of promettre, must actually view what is promised as preferable. An act doesn't count as a promise unless the promisor and promisee are each committed ${ }_{P R}$ to the priority. ${ }^{8}$

There are well-known difficulties for this view about the nature of promising (e.g. Grant 1949; Harnish 1990; Lauer 2013). First, there are cases in which one erroneously believes that the promisee has an interest in what is promised, as in (26).

(26) Clara promised her dying father that she would spread his ashes over the Seine, not realizing that he actually wanted them spread over the Saône.

Intuitively, Clara didn't merely try or intend to make a promise to her father; she actually did. In promises as threats the promisor even knows that the promisee wouldn't defend the priority, as in (27).

David promised his sister that he would make her life miserable.

It is precisely in making the promise-in committing to a course of action that his sister disprefers - that David threatens his sister. There may even be cases in which the subject of the promise doesn't view what is promised as preferable, as in (28).

\footnotetext{
8 I use 'promisor' and 'promisee' both in the successful cases, where the intended promise is made, and in the unsuccessful cases, where the act doesn't count as a promise.
} 
I promised the terrorist that I would kill the other hostages if he held off his plan for ten minutes. But I knew that the police were on their way, and that it would never come to that. I would never do such a thing.

The subject in (28) isn't "prepared to defend" the preferability of killing the hostages in any conversation. ${ }^{9}, 10$

P\&R might reply that examples such as (26)-(28) are exceptional cases of promising. P\&R might posit that insofar as the contextual commitment $P R$ condition is generally satisfied with promettre-or at least generally satisfied in paradigm cases of promising — promettre has become lexically associated with indicative mood. As with 'believe' and 'hope' in Sect. 3.1, such a move weakens the predictiveness of the account. It might be that in paradigm cases of promising both the subject and object are committed $_{P R}$ to what is promised, and so it might not be surprising to find languages such as French that lexicalize indicative with commissives. However, unlike 'believe' and 'hope', indicative-selection with commissives such as 'promise' is crosslinguistically robust. One is left wondering why some languages wouldn't treat the types of promises in (26)-(27), if not also (28), as relevant to mood selection. The positive account in Sect. 4 derives indicative-selection with commissives without assuming that contentious substantive assumptions about the nature of promising have been encoded in the conventional meaning across languages.

Now turn to P\&R's claims about the differences between promising and ordering vis-à-vis contextual commitment ${ }_{P R}$. There are two issues here which aren't delineated in P\&R's discussion (2012: 472-473, 480-481): (i) whether, upon performance of the utterance, it need be presupposed that the subject and object are prepared to defend the priority as preferable; and (ii) whether, upon performance of the utterance, the promise or order is "automatically in effect" (2012: 473), i.e. whether the priority is automatically added to the deontic ordering source. Neither way of understanding 9 Native French speakers in an Amazon Mechanical Turk task uniformly translated examples such as
(26)-(28) with indicative, as in (i) (see footnote 6). Likewise for examples such as (20) with croire; for (22)
with espérer, all participants but one used indicative. Thanks to an anonymous referee.

(i) David a promis à sa soeur qu'il rendrait sa vie misérable.

David has promised to his sister that he make.COND.IND her life miserable

10 A reviewer asks whether P\&R might address some of the counterexamples by weakening the commitment presupposition to a presupposition that the individual arguments have a disposition to defend the relevant propositions in the reported event $e$, rather than in any relevant conversation $c$. However, the commitment presupposition is about what the individuals are disposed in the reported event $e$ to do. The weakened presupposition-that the individuals are disposed in $e$ to defend the propositions $p \in h(e)$ in $e$-is still violated in contexts like (26)/(28) where the speaker knows that one of the individuals didn't have such a disposition in $e$. Could the presupposition be revised further, to require that every individual argument presuppose in $e$ that every individual argument is (would be?) disposed in $e$ to defend the proposition in $e$ ? In (26), although Clara's father wasn't actually prepared to defend the ashes-in-the-Seine priority, Clara assumed when making the promise (in $e$ ) that he was; likewise for (28). However, first, neither revised condition helps with examples such as (27) or non-transparency examples like (20)-(22) from Sect. 3.1 (see also the examples below with directives and permettre, and (36)-(38) with fiction verbs). Second, the revised conditions lead to problems with certain of P\&R's core examples. For instance, P\&R's explanation of the infelicity of espérer 'hope' in (15) turns on the fact that the king isn't prepared in the speech event $e^{*}$ - an event presumably among the "relevant" conversations - to defend his earlier desire for the bishop to be killed. 
contextual commitment ${ }_{P R}$ captures the mood-selection contrasts between commissives and directives.

$P \& R$ are correct that one can be ordered to do something that one doesn't think is preferable. So, on the one hand, if $\mathrm{P} \& \mathrm{R}$ take the relevant sense of commitment $P R$ to be as in (i), I agree that 'order' doesn't presuppose contextual commitment ${ }_{P R}$. However, as illustrated above, neither does 'promise'.

On the other hand, if $\mathrm{P} \& \mathrm{R}$ take the relevant sense of commitment $P R$ to be as in (ii), it is no longer clear that directives don't presuppose contextual commitment $P R$. Following Portner's seminal work, imperatives are often treated as directly updating the addressee's To-do List, the set of acts she is contextually committed to performing (Portner 2004, 2007; cf. Ninan 2005; Portner 2009; Charlow 2011). This view is taken to capture the oft-observed anomalousness of sentences such as (29).

\section{a. Leave! — \#even though I know you won't.}

b. \#Mary must leave now, but I know she won't.

(Portner 2009: 190)

Felicitously using an imperative commits the addressee to the priority in the sense of committing her to (intending to) satisfy it, at least for purposes of conversation. In Portner's and Rubinstein's broader work, imperatives and strong necessity modals are

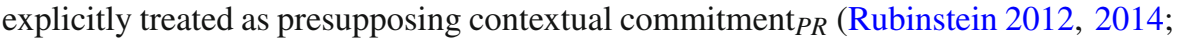
Portner and Rubinstein 2016). But if directive verbs report issuances of directives and themselves issue directives in performative uses, it is unclear why they would differ from other directive constructions with respect to contextual commitment $P R$.

Parallel concerns arise for predicates such as permettre 'permit'. On the one hand, 'permit' would seem to be like 'promise' in that the permitter and permittee typically both regard what is permitted to be of value to the permittee. One usually permits people do things they would want to do, as in (30). Examples such as (31) are typically anomalous.

(30) Elaine's mother permitted her to go to the party.

(31) \#I permit you to go to the library, but I know you don't want to.

On the other hand, there are cases in which the subject or object of 'permit' (like 'promise') doesn't find what is permitted to be preferable, as in (32)-(33).

(32) [Context: Elaine wants to go to the party later, instead of visiting her grandmother like she said she would. Elaine's mother would prefer that she Elaine not go to the party.]

Elaine's mother permitted her to go to the party, but it was really a test to see if Elaine would choose on her own to visit her grandmother.

(33) She permitted him to stay for dessert, not realizing that he was already full and wanted to leave the table.

What, then, would $\mathrm{P} \& \mathrm{R}$ predict about the mood-selection properties of permettre? Would they treat examples like (30) as the norm and predict that permettre (grammatically) selects indicative, as with promettre? Or would they predict that "because the commitment condition... is not in general satisfied" with permettre, in light of exam- 
ples like (32)-(33), permettre grammatically selects subjunctive, as with ordonner? (In fact permettre patterns with ordonner in selecting subjunctive.)

\subsection{Fiction verbs}

Fiction verbs ('dream', 'imagine') generally select indicative across languages; French is no exception. Though $\mathrm{P} \& \mathrm{R}$ don't discuss indicative-selection with fiction verbs, their remarks on veridicality suggest an explanation in terms of contextual commitment ${ }_{P R}$ :

Thinking about the indicative in terms of contextual commitment captures the persistent intuition in the literature that indicative-selecting attitudes take into account all the relevant things that an attitude holder takes to be true-be it in reality, in the context of a dream, or in a conversation (Farkas 1992; Giannakidou 1994, 1995, 1997, 1999; Quer 2001). An attitude holder would defend all and only those propositions that he or she thinks ${ }^{11}$ accurately describe the relevant "reality," and thus there is an overlap between Giannakidou's notion of veridicality and contextual commitment to epistemic backgrounds. (Portner and Rubinstein 2012: 482)

$\mathrm{P} \& \mathrm{R}$ 's response is too quick.

As we have seen, $P \& R$ treat indicative as requiring commitment to the specific content of a modal background; one must be prepared to defend the propositions in the modal base and ordering source as "rational/proper/sensible/wise" (2012: 475, 477-481). ${ }^{12}$ It isn't evident that the subjects of fiction verbs satisfy this condition. Suppose I imagine a world with unicorns, flying pigs, etc., so that the modal base for 'imagine' in (34) includes propositions that there are unicorns, that there are flying pigs, etc.

J'ai imaginé que les cochons volent.

I imagined that pigs fly.IND

I was not prepared to argue that there are unicorns, that there are flying pigs, etc. "in any relevant conversation." I might not even have been prepared to do so while I was imagining. Yet these are the propositions that "accurately describe the relevant 'reality'," i.e. what I was imagining.

\footnotetext{
11 P\&R smuggle in that the subject has a higher-order belief about the content of the modal background. This doesn't follow from their analysis as stated. See below.

12 Although P\&R are explicit about treating commitment $P R$ as commitment to the propositions in the modal base or ordering source, an additional complication arises in cases of uncertainty about the specific content of a modal background at the evaluation world/event. Suppose one endorses whatever the Pope demands, but one is unsure what he has actually demanded; or suppose one endorses the CIA's confidential evidence in the filing cabinet, but one is unsure what their evidence actually is. One might not be prepared to defend the specific propositions in $f_{\text {cia }}(e)$ or $g_{\text {pope }}(e)$ as "rational," etc., yet one is still intuitively committed to the modal background representing the CIA's evidence or the Pope's demands. P\&R might revise the account of commitment $P R$ to require having corresponding conditional dispositions, e.g. a disposition to defend $p$ given that the Pope said ! $p$. Yet this move would undermine their account of the anomalousness of (18b), where they "assum[e] that commitment to a preference, in the relevant sense, requires being aware of it” (2012: 471-472).
} 
It is worth unpacking these points. P\&R's contextual commitment presupposition requires that " $a$ is disposed/prepared in $e$ to argue for $h(e) \ldots$ in any relevant conversation $c$ " (2012: 477). It is important to be clear about the event in which the subject is presupposed to be "disposed/prepared to defend" the modal background, and what the disposition amounts to: one must have a certain disposition in the event $e$ described by the predicate; the disposition must be to defend such-and-such propositions in any relevant $c$. In $(34) /(35)$ the presupposition requires that the subject be prepared in the event of imagining/dreaming to defend that pigs fly.

Alice a rêvé que les cochons volent.

Alice dreamed that pigs fly.IND

Of course one needn't be prepared to defend that pigs fly in the actual circumstance - an event of, say, sitting at one's desk daydreaming, or lying in bed having an unconscious experience, ill-disposed to do much of anything. One could be in a permanent coma. But note that one needn't have the "disposition to defend" internal to the dream (imagining, etc.) either. We can dream that we don't have dispositions to defend things happening in our dreams, as in (37)-(38), schematized in (36).

J'ai rêvé/imaginé que $p$.IND et que je n'étais pas disposé à I imagined/dreamed that $p$.IND and that I was.IND not disposed to défendre que $p$

defend that $p$

a. $\approx$ "there was an event $e$, it was a dreaming/imagining event, of which $a$ was the agent, the content of which included (inter alia) $p$, and in which $a$ wasn't disposed to defend $p$ "

(37) I dreamed that there were aliens and I didn't believe that there were and would deny it forever.

(38) Trump: I had a terrible nightmare: I dreamed that global warming was real but I wouldn't stop denying it, right up until the end when it killed us all.

Wilder dreams have been had.

Distinguish (i) commitment $P R$, i.e. commitment to the specific content of a modal background, and (ii) commitment to thinking that a modal background correctly represents the relevant information or priorities. Could P\&R capture indicative-selection with fiction verbs by revising their account and treating the relevant notion of commitment as commitment in the sense of (ii)? No. Even putting aside examples such as (36)-(38), such a move excludes by linguistic fiat the possibility of non-transparency about one's attitudes (about the speech acts one is involved in, etc.; Sect. 3.1). One cannot refute Williamson by citing a French grammar. Even if one could, the individual arguments of subjunctive-selecting verbs satisfy the commitment condition in sense (ii) as well. The subject of vouloir in (39) may not be prepared to argue that her "glandular preference" for a cigarette is reasonable; she lacks sense-(i) commitment $P R$. But she is prepared to argue that an ordering source which includes the proposition that she has a cigarette accurately describes her glandular preferences; she has sense-(ii) commitment. 
(39) [Context: You are at your doctor's office for a checkup. He tells you what bad shape your lungs are in. If you continue to smoke, you will soon die.]

O mon Dieu! Avec tout ce stress, je veux/??j'espère vraiment fumer O my God with all this stress I want/??hope truly smoke.INF une cigarette dès que je sortirai.

a cigarette from that I leave

'Oh gosh, Doctor, with all this stress I really want/??hope to have a cigarette as soon as I leave!'

(Portner and Rubinstein 2012: ex. (24))

Likewise the subject in (40) may think that it is impossible to build a perpetual motion machine, and thus not be prepared to "argue in favor of all of the propositions which would need to be in the [modal base] in order for [(40)] to be true" (2012: 479). But she may still be prepared to argue that such propositions accurately describe the "reality according to her glandular desire," or how the world would need to be for a perpetual motion machine to be possible.

I want/??hope to build a perpetual motion machine.

(Portner and Rubinstein 2012: ex. (28))

Presupposing sense-(ii) commitment in (39)-(40) is nothing more than a general Quality commitment that what one is saying is true.

$\mathrm{P} \& \mathrm{R}$ aren't alone in having issues with fiction verbs. Indicative-selection with fiction verbs is puzzling from the perspective of traditional accounts of mood in terms of realis/irrealis since the contents of dreams, imaginings, etc. don't generally correspond to reality. A common move in response is to treat fiction verbs as analogous to other indicative-selecting verbs in representing a "reality," albeit a fictional one. Giannakidou expresses the idea well:

When I dream or imagine something, as a dreamer, I am fully committed to the fictional reality of my dream ... [F]ictional reality replaces the actual one...: dream shifts the model of evaluation ... to the [model of the dreamer, i.e. the set of worlds compatible with the subject's dream]. All worlds in that space are $p$ worlds, since reality no longer plays a role.... This suggests that the grammar treats fictional contexts as shifted, non-partitioned states where veridicality holds as if in the real world. Hence, dream and fiction verbs are subjectively ... veridical. (Giannakidou 2016: 21-22)

This is unexplanatory. Any modal backgrounds characterize a set of "best worlds" at which a proposition may be true or false. ${ }^{13}$ One's desires characterize a set of worlds that best satisfy one's desires, a "desire model" representing "the ideal reality of one's desires." Why, then, do natural languages systematically treat "fictional realities," but not the "ideal realities" of subjects' desires, as relevantly like actuality? Or treat dreaming, but not wanting, as generally involving a kind of commitment relevantly like the commitment in (say) knowing? An account of the operative notions of "reality"

13 In Kratzerian terms (given the limit assumption): a set of $\lesssim g(w)$-minimal worlds in $\bigcap f(w)$. 
or "commitment" must be provided to explain the relevant similarity between fiction verbs and other indicative-selecting verbs. Intuitive appeals to fictional realities or commitment "in the context of a dream" are insufficient.

\subsection{Recap}

Let's recap. $P \& R$ argue that what distinguishes indicative-selecting verbs in French is that they presuppose contextual commitment ${ }_{P R}$ to the verb's modal backgrounds: indicative-selecting verbs presuppose that every individual argument of the verb is prepared to defend the reasonableness of the specific propositions in the modal base and ordering source; subjunctive-selecting verbs lack this presupposition. I argued that P\&R's understanding of "contextual commitment to a modal background" doesn't capture subjunctive-selection with emotive factives, indicative-selection with croire or verbs of fiction, or the contrasting mood-selection properties of espérer versus vouloir or promettre versus ordonner. Pace P\&R, it isn't in "the nature of" believing, hoping, promising, etc. that the subjects/objects are disposed to defend the information or priorities in question "in any relevant conversation" (2012: 477). I suggested that $P \& R$ might revise their view and treat the relevant indicative-selecting predicates as grammatically associated with indicative, parallel to how $\mathrm{P} \& \mathrm{R}$ treat certain subjunctive-selecting predicates as grammatically associated with subjunctive. Yet such moves threaten the explanatory and predictive power of P\&R's semantic analysis of mood in terms of contextual commitment $P R$, even for the central puzzle cases which the account was designed to explain. The distinction between predicates that do/don't presuppose contextual commitment $P R$ cuts across the distinction between indicative-selecting/subjunctive-selecting predicates. ${ }^{14}$

The following section develops an alternative approach to integrating a notion of commitment in an account of verbal mood. The proposed analysis of mood provides a more explanatory treatment of the core puzzle cases from Sects. 1-3. The account derives the relevant mood-selection data without relying on grammaticalized mood or treating contentious substantive assumptions about the nature of promising, etc. as conventionalized in the semantics. Appeals to informal notions such as "visceral"/"glandular" attitudes versus "intellectual" attitudes, or commitments "in the context of a dream," won't be required.

\section{Mood selection and states of mind}

A key innovation in P\&R's account is to treat mood selection as fundamentally depending on a relation between individuals' attitudes and the embedding predicate's modal

\footnotetext{
14 In closing their discussion P\&R suggest that contextual commitment may help explain linguistic phenomena beyond mood selection (2012: 484). For instance, Rubinstein (2012) argues that what distinguishes weak necessity modals ('ought', 'should') and strong necessity modals ('must', 'have to') is that strong necessity modals presuppose collective commitment $P R$ to the relevant modal backgrounds, and weak necessity modals presuppose a lack of collective commitment ${ }_{P R}$. See Silk (2018) for extended critical discussion, and an alternative account of the weak vs. strong necessity modal distinction and interactions with contextual assumptions. It isn't commitment to the content of modal backgrounds that explains differences in mood selection or modal strength.
} 
backgrounds, rather than (e.g.) on attitudes about the truth value of the complement. P\&R's general strategy is to explain mood selection in terms of whether relevant individuals are "committed," in a qualitatively defined sense, to the predicate's modal backgrounds. An alternative approach — the one I wish to explore here-is to explain mood selection in terms of whether the relation between the predicate's modal backgrounds and a relevant overall state of mind represents a relation of commitment. I call this general approach a state-of-mind approach to verbal mood.

To preview: I propose that indicative mood in French presupposes that the predicate's modal backgrounds are "live" (in a manner to be made precise) from the perspective of the state of mind characterizing the event described by the predicate. Indicative-selecting predicates "presuppose commitment," not in the sense of presupposing a commitment to the truth of the complement or of presupposing a disposition to defend the reasonableness of the propositions in the predicate's modal base/ordering source, but in the sense of presupposing that the informationalevaluative state determined by the predicate's modal backgrounds is a substate of the informational-evaluative state characterizing the local attitude/discourse event. These ideas can be given a perspicuous formalization. The account captures the core moodselection puzzles from Sect. 1, and provides an improved treatment of the examples from Sect. 3 which posed challenges for P\&R. Patterns of mood selection are derived from the proposed semantics of mood, independently attested features of the verbs' semantics, and general principles of interpretation.

\subsection{Background and analysis}

The state-of-mind approach analyzes verbal mood in terms of a relation between a predicate's modal backgrounds and a representation of an overall state of mind-in French, a representation of the state of mind characterizing the event described by the predicate. How one implements the approach will depend on one's broader views about the morphosyntax and semantics of the embedding predicates and of the root and embedded clauses, and one's substantive views about the representation of context and attitude states. Let's start with the latter.

It's common to include in a model of context a parameter representing information taken for granted for the purposes of conversation. This background information, or common ground $(C G)$, delimits the set of live possibilities in the discourse, i.e. the worlds among which the participants intend to distinguish, or context set $(C S=\bigcap C G$ ) (Stalnaker 1978, 2014; Clark 1996). In making assertions we winnow down the context set and settle on a more complete picture of the world. Yet conversation doesn't just involve sharing information. Inquiry is, in part, inquiry about what to do. It is thus also common to include a parameter representing norms or priorities accepted for purposes of conversation (Lewis 1979; Lochbaum 1998; Portner 2004, 2007; Starr 2010; Charlow 2011; Rubinstein 2012; Zanuttini et al. 2012). These contextual parameters determine a preordered set $\left(C S, \lesssim_{C P}\right)$ - the set of live possibilities $C S$ preordered in 
light of the accepted body of priorities $C P$. This represents the discourse context, the body of information and priorities presumed available for communication. ${ }^{15}$

Just as concrete discourse contexts can be represented by a body of information and priorities, so too subjects' concrete (content-bearing) attitudes and overall states of mind. For a discourse, the information is $C G$ and the priorities are $C P$, yielding a preordered set of live possibilities $\left(C S, \lesssim_{C P}\right)$. For an attitude, the representation targets information and priorities characterizing the attitude event-for instance, the subject's propositional beliefs $D O X$ and desires $D E S$, yielding a preordered set of doxastic alternatives $\left(\bigcap D O X, \lesssim_{D E S}\right)$.

A central insight in Hacquard's (2006, 2010; Anand and Hacquard 2014) work on modal and attitude semantics is the linguistic importance of a distinction between content-bearing and non-content-bearing events, and a notion of the content characterizing an event. A distinctive feature of attitude and speech events is that they are conceptualized as having informational content. The present appeal to states of mind generalizes these ideas and extends them to the domain of verbal mood. The state of mind characterizing an (attitude, speech) event may include both doxastic and broadly evaluative aspects.

Call a pair of a body of information and body of priorities a modal state. Our hypothesis about mood selection in French can be characterized in terms of a relation between the modal state determined by the predicate's modal backgrounds and the modal state representing the state of mind characterizing the event described by the predicate. To fix ideas I follow P\&R in treating mood morphemes in complement clauses as licensed by mood features adjoined to the embedding predicate, as in (41)-(42). Lexical entries for the indicative-licensing feature and subjunctive-licensing feature are given in (44)-(45). Simplified truth conditions for (41) follow in (46). (Like P\&R, I follow Hacquard $(2006,2010)$ in treating modal backgrounds as relativized to events, and I assume that the predicate's individual arguments are introduced by thematic roles. SoM is a partial function from events $e$ to preordered sets of worlds representing the informational-evaluative content of the state of mind characterizing $e$. More on these points below.) $)^{16}$

Alice $\left[\left[\left[{ }_{+}+i n d\right]\right.\right.$ croit $\left.\left.] f\right] g\right]$ que Blanche être-ind végétarienne. Alice thinks that Blanche be-indic vegetarian

Alice $\left[\left[\left[{ }_{+} \_s b j v\right]\right.\right.$ veut $\left.\left.] f\right] g\right]$ que Blanche être-sbjv végétarienne. Alice thinks that Blanche be-sbjv vegetarian

\footnotetext{
15 I ignore potential further parameters such as for the Question Under Discussion (Roberts 1996; Ginzburg 2012), or explicit representations of interlocutors' individual public commitments (Gunlogson 2001, 2008; Farkas and Bruce 2010; Lauer 2013; Malamud and Stephenson 2015).

16 The presuppositions in (44)/(46) use the ordering semantics formalization in (43a). The alternative formalizations aren't strictly speaking equivalent, since the relation between the preorders $\lesssim, \lesssim^{\prime}$ in (43a) is restricted to worlds in the respective preordered sets. This is to reflect the conceptual idea that mood selection is sensitive to a relation between informational-evaluative states. Insofar as one treats the preordered sets of worlds as basic in the representation of such states, it is natural to restrict attention in this way.
} 
Live modal states (ordering semantics, premise semantics)

Let $F, F^{\prime}, G, G^{\prime}$ be sets of propositions; let $S, S^{\prime}$ be sets of worlds; and let $\lesssim, \lesssim$ be preorders on worlds.

a. $(S, \lesssim) \unlhd\left(S^{\prime}, \lesssim^{\prime}\right)$-read: the modal state $(S, \lesssim)$ is live from the perspective of $\left(S^{\prime}, \lesssim^{\prime}\right)$-iff $(S, \lesssim)$ is a subpreorder of $\left(S^{\prime}, \lesssim^{\prime}\right)$, i.e. iff $S \subseteq S^{\prime} \wedge\left(\lesssim \cap S^{2}\right) \subseteq\left(\lesssim^{\prime} \cap S^{\prime 2}\right)$, where $X^{2}=\{\langle i, j\rangle: i \in X \wedge j \in X\}$. b. $(F, G) \unlhd\left(F^{\prime}, G^{\prime}\right)$ iff $F \supseteq F^{\prime} \wedge G \supseteq G^{\prime}$.

$$
\begin{aligned}
& \llbracket\left[+\_i n d\right] \rrbracket^{w}=\lambda P \lambda f \lambda g \lambda p \lambda e:(\cap f(e), \lesssim g(e)) \unlhd \operatorname{SoM}(e) . P(f)(g)(p)(e) \\
& \llbracket\left[+\_s b j v\right] \rrbracket^{w}=\lambda P \lambda f \lambda g \lambda p \lambda e . P(f)(g)(p)(e) \\
& \llbracket(41) \rrbracket^{w} \text { is defined only if }\left(\bigcap f_{b e l}(e), \lesssim g_{b e l}(e)\right) \unlhd \operatorname{SoM}(e) .
\end{aligned}
$$

When defined, $\llbracket(41) \rrbracket^{w}=1$ iff $\exists e[e$ in $w \wedge \operatorname{bel}(e) \wedge \exp (e, A) \wedge$ for every $\lesssim_{g_{b e l}(e)}$-minimal world $w^{\prime}$ in $\bigcap f_{\text {bel }}(e)$, Blanche is vegetarian in $\left.w^{\prime}\right]$

The subjunctive feature, $\left[+\_s b j v\right]$, is semantically vacuous. [+_sbjv] appears when more contentful mood features, such as [+_ind], are unavailable; in this sense it serves as a semantic default (Portner 1997; Schlenker 2005; Marques 2009; Siegel 2009; Portner and Rubinstein 2012). The indicative feature, [+_ind], is the semantically marked case. Roughly put, indicative mood in a clause is associated with a presupposition that the modal evaluation of the clause only considers worlds and evaluative relations that aren't excluded by the information and priorities characterizing the local attitude/discourse event. [+_ind] requires that the modal state determined by the predicate's semantics $\left(\bigcap f_{P}(e), \lesssim g_{P}(e)\right)$ - the modal state figuring in the compositional semantic evaluation of the complement- be live in the sense of being included in, or a substate of, the modal state $\operatorname{SoM}(e)$ representing the informational-evaluative content ("state of mind") of the event described by the predicate. The proposal admits of an elegant formalization: the preordered set $\left(\bigcap f_{P}(e), \lesssim_{P}(e)\right)$ must be a subpreorder of $\operatorname{SoM}(e)$.

Our representations of concrete discourses and attitude states could be complicated in various ways. For instance, Portner $(2007,2004)$ associates each interlocutor with her own To-do List, and treats the elements of To-do Lists as properties. The evaluative component in representations of discourses and attitudes could also be partitioned into subtypes or treated as a sequence in order to explicitly represent different types of priorities (cf. Portner 2007). The presupposition in (44) could be revised accordingly to require that the preorder determined by the predicate's modal background $g_{P}$ be a subset of the relevant coordinate/subtype of the priority-based sequence/partition in $\operatorname{SoM}(e)$. Given our purposes I bracket such potential complications. In general, what will be important for mood selection is whether the modal parameter in question bears the appropriate logical relation to the analogous component in the representation of context/attitudes. In the explanations to follow I assume that the preorders/premise sets represent priorities of the relevant type, and I treat contextual bodies of priorities, like ordering sources, as sets of propositions.

The remainder of the section applies the above analysis to the mood-selection puzzles from Sect. 1. First, a general remark on the theoretical status of "states of mind" and their role in explaining mood data will be helpful. I use the metalanguage predicate ' $S o M$ ' as a convenient shorthand for a relation between events and repre- 
sentations of informational-evaluative states; SoM isn't something lexically specific like modal backgrounds (cf. Hacquard's (2006, 2010) metalanguage 'CON' predicate). So it is misplaced to ask about the state of mind "associated with" specific predicates, like one might ask about the modal backgrounds of 'want' versus 'hope', etc. My only assumption is that concrete discourse events and concrete attitude eventsthe sorts of events described by speech-act predicates and attitude predicates-have informational-evaluative content as indicated above: for a discourse event $e, \operatorname{SoM}(e)$ may represent the mutually presupposed information and priorities in $e,\left(C S_{e}, \lesssim_{C P_{e}}\right)$; for an attitude event $e, \operatorname{SoM}(e)$ may represent the subject's doxastic+affective state in $e$, e.g. $\left(\bigcap D O X_{e}, \lesssim D E S_{e}\right) \cdot{ }^{17}$ The goal in what follows is to derive the mood-selection data from (i) this general assumption about the informational-evaluative content of discourse events and attitude events, (ii) independent linguistic evidence about the predicates' specific modal backgrounds, and (iii) general interpretive principles.

\subsection{Applications}

This section applies the proposal from Sect. 4.1 to the central puzzle cases discussed in Sects. 1-3. I start in Sects. 4.2.1-4.2.4 with attitude predicates (narrowly construed); Sects. 4.2.5-4.2.6 turn to speech-act predicates.

\subsubsection{Indicative-selection with croire}

Croire 'believe' takes a doxastic modal base $f_{\text {bel }}(e)$ representing the beliefs of the agent of $e$. Croire might take an additional doxastic modal background as ordering source, e.g. reflecting the subject's attitudes about normality or probabilities. For simplicity we can bracket this potential complication, and treat doxastic ordering sources $g_{b e l}$ and preorders $\lesssim_{d o x}$ as trivial in representations of context and attitudes. As an attitude verb, croire describes an aspect of an attitude event $e$. The informational-evaluative content of the event - the "state of mind" characterizing it, $\operatorname{SoM}(e)$ - is the subject's overall doxastic-evaluative state of mind. Hence the presupposition of [+_ind] is invariably satisfied, since the predicate's modal base and ordering source are equivalent to the analogous components in the representation of the subject's state of mind (see Sect. 4.1): $f_{b e l}(e)=D O X_{e}$, and $\lesssim_{b e l}(e)=\lesssim_{d o x_{e}}=\lesssim \emptyset$. Given a principle such as Maximize Presupposition! (Heim 1991), ${ }^{18}$ indicative mood is selected.

This account of croire avoids the difficulties with P\&R's account discussed in Sect. 3.1. Recall, for instance, (20) and (23), reproduced below.

[Context: Same as (20)]

a. Bert doesn't fully realize it yet, but he thinks that women are less capable than men in the workplace, and that their proper place is in the home.

\footnotetext{
17 I use ' $D O X_{e}$ ' as short for ' $\operatorname{DOX}(\iota x \exp (e, x), w)$ ', the set of propositions representing the beliefs of the subject/experiencer of $e$; likewise for ' $D E S_{e}$ ' and the subject's desires.

18 To a first approximation: when sentences $S$ and $S^{\prime}$ are contextual alternatives with the same asserted content and $S^{\prime}$ has stronger presuppositions, use $S^{\prime}$.
} 
b. Bert thinks that women are less capable than men in the workplace, but he would deny it if you asked him.

The indicative presupposition in (44) doesn't require that the subject be disposed to argue for the propositions in $f_{b e l}(e)$. It requires that the modal state figuring in the predicate's semantics be included in the modal state representing the subject's state of mind-here, that $\bigcap f_{b e l}(e) \subseteq \bigcap D O X_{e}$. Whether the subject is introspectively aware of her state of mind, and how exactly her state of mind is manifested in her (verbal) dispositions, are other matters.

\subsubsection{Indicative-selection with fiction verbs}

The above account of indicative-selection with croire can be extended to fiction verbs. For instance, rêver 'dream' takes a modal base that represents the content of the subject's dream. (As with croire, let's assume the ordering source is empty.) As an attitude verb, rêver describes an attitude event, namely a dreaming event $e$. The informational-evaluative content of $e, \operatorname{SoM}(e)$, is the content of the dream. Hence the presupposition of [+_ind] is invariably satisfied: as with croire, it is trivially the case that $\left(\bigcap f_{\text {dream }}(e), \lesssim g_{\text {dream }}(e)\right) \unlhd \operatorname{SoM}(e)$; the modal states are equivalent. A state-ofmind approach gives precise expression to intuitive appeals to "fictional realities" or commitments "in the context of a dream" in previous accounts (Sect. 3.3).

\subsubsection{Indicative-selection with espérer versus subjunctive-selection with vouloir}

Espérer 'hope' and vouloir 'want' are both desire verbs, yet espérer selects indicative and vouloir selects subjunctive. As attitude verbs they describe aspects of attitude events $e$. The type of informational-evaluative content of the events is the same: $\operatorname{SoM}(e)$ represents the subject's overall state of mind. The contrast in mood selection between espérer and vouloir can be derived from the relation between this common element and independently attested differences in the verbs' semantics.

Let's start schematically. Suppose we have some desire predicate ' $D$ '; its ordering source $g_{D}$ represents the subject's desires, and we are inquiring about the relation between its modal base $f_{D}$ and the subject's beliefs. It is common in work on modal expressions to posit a diversity condition on modal bases in order to avoid trivialities in the derivation of truth conditions (Frank 1996; Condoravdi 2002; Werner 2003; terminology varies). For present purposes we can treat such a condition as requiring that any non-empty ordering source non-trivially distinguish among worlds in the modal base with respect to the embedded proposition $p$-formally, that for any $g(e) \neq \emptyset$, there is some $p$-world $u$ and some $\neg p$-world $v$ in $\bigcap f(e)$ such that $u \lesssim g(e) v \vee v \lesssim g(e) u$. Given the diversity condition, $\bigcap f_{D}(e)$ must include some $\neg p$-worlds, for any use of ' $D$ ' with complement ' $p$ '. There are various ways the satisfaction of this requirement might play out in the lexical semantics and behavior of the predicate. ' $D$ ' might take a modal base that represents the subject's beliefs, i.e. $f_{D}=D O X$. Sentences ' $x D p$ ' would then imply that $x$ 's beliefs are compatible with $\neg p$. Alternatively, ' $D$ ' might take a modal base that represents some subset of the subject's beliefs, so that $\bigcap f_{D}(e) \supset \bigcap D O X_{e}$. Sentences ' $x D p$ ' then needn't imply that $x$ takes $\neg p$ to be 
possible, since the $\neg p$-worlds in $\bigcap f_{D}(e)$ satisfying the diversity condition may be outside $x$ 's doxastic alternatives, i.e. in $\bigcap f_{D}(e)-\bigcap D O X_{e}$.

I suggest that 'hope' and 'want', and their crosslinguistic correlates, lexicalize precisely these options. The contrasting mood-selection properties of espérer and vouloir fall out given (i) our (linguistic) analysis of mood morphemes and (ii) our general (non-linguistic) assumption that the informational-evaluative content of an attitude event represents the subject's overall state of mind. Put another way, we can reason as follows: Assume as a working hypothesis that espérer and vouloir both take ordering sources representing the subject's desires. The predicates' mood-selection properties can be derived from independent linguistic evidence about the predicates' modal bases, given the diversity condition, and the relation between these modal bases and subjects' beliefs. (We will revisit the assumption that both predicates' ordering sources represent the subject's desires below.)

Start with vouloir 'want'. Consider (48) from Heim, French variant in (49).

(48) (John hired a babysitter because) he wants to go to the movies tonight.

(Heim, 1992, ex. (44))

Jean a embauché une baby-sitter parce qu'il veut que nous allions.SBJV Jean has hired a babysitter because he wants that we go.SBJV au cinéma.

to the movies

As Heim notes, (48) is compatible with John's being certain about whether he will go to the movies tonight. If the modal base for 'want' was identified with the subject's beliefs, every world in $\bigcap f_{\text {want }}(e)$ would be a world in which John goes to the movies. Since 'want' takes a non-trivial ordering source (representing, say, the subject's desires), the diversity condition on modal bases would be violated. The felicity of examples such as $(48) /(49)$ thus indicates that $f_{\text {want }}$ cannot be identified with the subject's beliefs. This leads Heim to treat $\bigcap f_{\text {want }}(e)$ as a superset of the subject's doxastic alternatives-specifically, as representing what the subject believes to be the case no matter how she chooses to act (Heim 1992: 199). ${ }^{19}$ So, $\bigcap f_{\text {want }}(e) \nsubseteq \bigcap D O X_{e}$. So, the presupposition in (44) is violated- $\left(\bigcap f_{\text {want }}(e), \lesssim g_{\text {want }}(e)\right) \nsupseteq S o M(e)$ 一and the subjunctive-licensing feature [+_sbjv] must be used with vouloir. Subjunctiveselection with vouloir can be derived from independently motivated treatments of the predicate's modal backgrounds.

19 Heim's specific treatment of $f_{\text {want }}$ may need to be refined to cover cases where one's certainty that $p$ is due to beliefs about other events regarded as depending on one's desires, as in (i).

(i) [Context: You have a genie who has perfect knowledge of your mental states and will ensure that your desires today get satisfied no matter whether you choose to do anything to satisfy them. You know you're about to become unconscious until tonight. Before doing so, you say:]

I'm calling a babysitter because I want to go to the movies tonight.

To a first approximation, $f_{\text {want }}(e)$ might be identified instead with what the subject believes to be the case no matter what she desires. We can put such issues about the specific lexical semantics aside. What is important for matters of mood selection is simply that $\bigcap f_{\text {want }}(e) \nsubseteq \bigcap D O X_{e}$. 
This derivation of subjunctive-selection with vouloir captures subjunctive-selection with related expressions of intention, such as l'intention est que in (50).

L'intention est qu'il aille au cinéma.

The intention is that he go.SBJV to the movies.

Like (48), (51) is felicitous even if John is certain that he will go to the movies tonight (assuming he isn't certain that he will go no matter what he chooses to do).

$$
\text { John intends to go to the movies tonight. }
$$

(Heim 1992: 199)

The modal base for expressions of intention $\bigcap f_{\text {int }}(e)$ is like the modal base for 'want' in being a superset of the doxastic alternatives $\bigcap D O X_{e}$ (Heim 1992: 199). This correctly predicts subjunctive-selection with expressions such as l'intention est que.

Subjunctive-selection with expressions of intention poses a challenge for P\&R's contextual commitment account. It is hard to see why a subject wouldn't be prepared to defend what she intends to do.

The above examples highlight an important contrast between 'want'/'intend' and 'hope'. Whereas (48)-(49) are felicitous even if John is certain about whether he will go to the movies, (52)-(53) with 'hope' are not.

(52) ??(John hired a babysitter because) he hopes to go to the movies tonight.

(53) ??Jean a embauché une baby-sitter parce qu'il espère que nous allons.IND

Jean hired a babysitter because he hopes that we go.IND

au cinéma.

to the movies

This contrast makes sense on the hypothesis that the modal base for 'hope' is the subject's beliefs. Since 'hope' takes a (bouletic) ordering source, the diversity condition requires that there be some $\neg p$-worlds in the modal base. Treating fhope as DOX correctly predicts that (52)-(53) imply that John is leaving open the possibility that he might do something other than go to the movies later-hence the infelicity in the given context. Indeed we already saw evidence for treating the modal base for 'hope' in this way in Sect. 3.3: (54) is anomalous if the subject thinks that building a perpetual motion machine is impossible.

(54) ??I hope to build a perpetual motion machine.

Treating $f_{\text {hope }}$ as $D O X$ reflects the common idea that 'hope'-ascriptions require that the subject believes the complement is possible.

So, examples such as (52)-(54) provide independent support for treating the modal base $f_{\text {hope }}(e)$ as representing the subject's beliefs. Given that the ordering source $g_{\text {hope }}(e)$ represents the subject's desires $\left(=D E S_{e}\right)$, the presupposition of $\left[+\_i n d\right]$ is invariably satisfied: The modal state $\left(\bigcap f_{\text {hope }}(e), \lesssim g_{\text {hope }}(e)\right)$ determined by the predicate's modal backgrounds is live from the perspective of the representation of the subject's state of mind $\left(\bigcap D O X_{e}, \lesssim D E S_{e}\right)$ (Sect. 4.1). So espérer selects indicative. 
These accounts of indicative-selection with espérer and subjunctive-selection with vouloir capture the conversational contrasts observed in Sects. 2-3. First, recall (15) and (39) from P\&R, reproduced in (55)-(56), respectively. (For space purposes I only include the English translations. Below, let killed be the proposition that the bishop is killed, and cig be the proposition that the subject has a cigarette.)

[Context: Same as (15)]

a. ?? But you hoped for him to be killed!

b. But you wanted him to be killed!

[Context: Same as (39)]

a. ?? Oh gosh, Doctor, with all this stress I really hope to have a cigarette!

b. Oh gosh, Doctor, with all this stress I really want to have a cigarette!

(from Portner and Rubinstein 2012: exs. (24)-(25))

In typical contexts for (55) it would be assumed that, given the king's authority, if the king wants something done, it gets done (or at least it would be assumed that the king takes himself to have such authority). So, since the king desires to have the bishop killed, it would be assumed - at least for purposes of conversation-that the king believes that the bishop will get killed. So, $\bigcap f_{\text {hope }}(e) \subseteq$ killed, violating the diversity condition-hence the anomalousness of (55a) with espérer 'hope'. Similarly, in (56) the subject is plausibly assuming - at least for purposes of conversation-that she won't in fact have a cigarette when she leaves. So, $\bigcap f_{\text {hope }}(e) \subseteq \neg$ cig-hence the anomalousness of (56a). By contrast, the modal bases $\bigcap f_{\text {want }}(e)$ in the (b)-examples with vouloir 'want' can include worlds outside the subject's doxastic alternatives. The modal base in (55b) includes worlds that differ with respect to the bishop's being killed, and the modal base in (56b) includes worlds that differ with respect to the patient's having a cigarette. The diversity condition is satisfied. Given the subjects' desires, the 'want'-ascriptions can thus be felicitous and true.

This diagnosis assimilates the contrasts between $(55 a) /(56 a)$ and $(55 b) /(56 b)$ with the contrast between $(48) /(49)$ and $(52) /(53)$; the contrasts are treated as due to differences in modal base. Yet we saw in Sects. 2-3 that P\&R treat the infelicity of 'hope' in (55)-(56) in terms of the subject's unwillingness to defend the relevant desire. The felicity of 'hope' in the alternative contexts in (57)-(58) speaks against explaining the contrasts in (55)-(56) in terms of differences in ordering source: the contexts in $(55) /(56)$ and $(57) /(58)$ are equivalent vis-à-vis the relevant ordering source and the subject's commitments to the relevant desires.

(57) [Context: The king writes in his private journal about how annoyed he is with the bishop. Unbeknownst to the king, the knights stumble across the journal, read the entry about the bishop, and go ahead and kill him. When the king hears about it, he is angry. The knights say:]

But you hoped he would die!

(58) [Context: In your last appointment the doctor told you that if you continued to smoke, you would soon die. At the time you were out of cigarettes, and you weren't sure whether you would be able to get more after leaving the office. 
In your next visit, you recount your experience and say:]

With all the stress I really hoped to have a cigarette as soon as I left!

Our above modal-base explanation correctly predicts that the 'hope'-ascriptions should improve in contexts where the subject isn't assumed to have a specific belief about the complement, as in (57)-(58).

That said, the account of mood in Sect. 4.1 is compatible with explaining instances of mood selection in terms of properties of the ordering source: the presupposition of $\left[+\_i n d\right]$ is violated if the predicate's preorder $\lesssim_{g_{P}(e)}$ includes evaluative relations that aren't represented in the subject's priorities of the relevant type (Sect. 4.1). P\&R's example in (19), reproduced in (59), may provide precisely such a case.

\section{a. ?? J'espère épouser Alice, et j'espère épouser Sue. \\ ?? I hope to marry Alice and I hope to marry Sue \\ b. Je veux épouser Alice, et je veux épouser Sue. \\ I want to marry Alice and I want to marry Sue}

Suppose we give espérer 'hope' the semantics of an ordinary necessity modal-i.e., requiring that the embedded proposition is true at every $\lesssim g_{\text {hope }}(e)$-minimal world in the modal base $\bigcap f_{\text {hope }}(e)$ - parallel to the semantics for croire in (46).

$$
\begin{aligned}
& \llbracket x \text { espérer } p \rrbracket^{w} \text { is defined only if }\left(\bigcap f_{\text {hope }}(e), \lesssim g_{\text {hope }}(e)\right) \unlhd \operatorname{SoM}(e) . \\
& \text { When defined, } \llbracket x \text { espérer } p \rrbracket^{w}=1 \text { iff } \exists e\left[e \text { in } w \wedge \text { hope }(e) \wedge \exp \left(e, \llbracket x \rrbracket^{w}\right) \wedge\right. \\
& \text { for every } \left.\lesssim g_{\text {hope }}(e) \text {-minimal world } w^{\prime} \text { in } \bigcap f_{\text {hope }}(e), \llbracket p \rrbracket^{w^{\prime}}=1\right]
\end{aligned}
$$

On such a semantics, a conjunction of the form ' $x$ hopes $p$ and $x$ hopes $q$ ', for (contextual) contraries $p$ and $q$, cannot be (non-vacuously) satisfied relative to constant modal backgrounds $f_{\text {hope }}$ and $g_{\text {hope }}$ for both conjuncts. Even allowing for intra-sentential shifts in modal backgrounds, the indicative presupposition precludes the possibility of satisfying such conjunctions by interpreting each conjunct relative to different subsets of the subject's desires. This presupposition requires the ordering source $g_{\text {hope }}(e)$ to be a (possibly improper) superset of $D E S_{e}$. Hence the ordering source for each conjunct of (59a) must represent the contents of both of the conflicting desires; it must include both the proposition that $x$ marries Alice (alice) and the proposition that $x$ marries Sue (sue). So, given that $x$ cannot marry both Alice and Sue, the alice-worlds in the modal base are $\lesssim g_{\text {hope }}(e)$-incomparable to the sue-worlds, and (59a) cannot be true.

In contrast, (59b) with vouloir lacks the proposed indicative constraint on the ordering source. This allows for the possibility of having an ordering source that represents a relevant subset of the subject's desires. (59b) can be true even if vouloir is given an ordinary semantics of necessity like espérer, universally quantifying over a set of minimal accessible worlds: the first conjunct can be true relative to the Alice-relevant subset of the subject's desires, say $g_{\text {want }}^{1}(e)=\{$ alice $\}$, and the second conjunct can be true relative to the Sue-relevant subset of the subject's desires, say $g_{\text {want }}^{2}(e)=\{$ sue $\}$. In effect, the shift in relevant subsets of $D E S_{e}$ allows one to bracket inconsistencies/incomparabilities in the subject's overall desires. Although the aliceworlds in $x$ 's doxastic alternatives are $\lesssim D E S_{e}$-incomparable to the sue-worlds-i.e. $\langle a, s\rangle \notin \lesssim D E S_{e} \wedge\langle s, a\rangle \notin \lesssim D E S_{e}$ for any alice-world $a$ and sue-world $s$ in $\bigcap D O X_{e}-$ 
the predicate's preorder $\lesssim_{g_{\text {want }}(e)}$ can relate worlds in ways that are excluded by $D E S_{e}$. So, (59b) is true insofar as (i) every $\lesssim_{g_{\text {want }}^{1}(e)}$-minimal relevant world is an alice-world, and is $\lesssim_{g_{\text {want }}^{1}(e)}$-better than any sue-world; and (ii) every $\lesssim_{g_{\text {want }}^{2}(e)}$-minimal relevant world is a sue-world, and is $\lesssim_{g_{\text {want }}^{2}(e)}$-better than any alice-world. "Bouletic dilemmas" are coherently expressible with vouloir 'want' and not with espérer 'hope'. ${ }^{20}$

\subsubsection{Subjunctive-selection with emotive factives}

Emotive factives are prima facie puzzling from the perspective of a commitmentbased approach to mood selection: If emotive factives imply commitment to their complements, why do they generally select subjunctive in French? Whence the contrast between (61) with the emotive factive être heureux 'be happy', and (62) with the nonemotive factive savoir or desiderative espérer?

(61) Alice est heureuse que Blanche soit végétarienne.

Alice is happy that Blanche is.SBJV vegetarian

Alice sait/espère que Blanche est végétarienne.

Alice knows/hopes that Blanche is.IND vegetarian

Our account of mood from Sect. 4.1 provides a solution: Subjunctive-selection with emotive factives follows from the combination of their factivity implication and the diversity condition on modal bases. The factivity of etre heureux requires (at least) that the subject believes the embedded proposition $p$, i.e. that $\bigcap D O X_{e} \subseteq p$; (61) implies that Alice believes that Blanche is vegetarian. So, if the modal base was identified with the subject's beliefs, $p$ would be true throughout the modal base. This would violate the diversity condition, given that the predicate takes a non-trivial (bouletic) ordering source. One isn't happy about everything one believes to be the case. So, the modal base $\bigcap f_{\text {happy }}(e)$ must include some $\neg p$-worlds. So, $\bigcap f_{\text {happy }}(e) \nsubseteq \bigcap D O X_{e}$, and the presupposition of $\left[+\_i n d\right]$ is violated: $\left(\bigcap f_{\text {happy }}(e), \lesssim g_{\text {happy }}(e)\right)$ isn't included

\footnotetext{
20 For the sake of argument I have assumed that 'want' has the same sort of necessity semantics as 'hope'. There may be independent reasons for weakening the semantics of 'want' in ways that would also allow for the consistency of (59b) (see Lassiter 2011). For instance, consider the truth conditions in (i), adapted from Swanson's (2011) semantics for the weak necessity modal 'ought' (modified to make the limit assumption). (A $\lesssim$ chain is a totally preordered subset of a partial preorder $\lesssim$ of a set of worlds; a maximal $\lesssim$ chain is a $\lesssim$ chain that isn't a proper subset of any $\lesssim$ chain.)

(i) $\llbracket x$ vouloir $p \rrbracket^{w}=1$ iff $\exists e\left[e\right.$ in $w \wedge \operatorname{want}(e) \wedge \exp \left(e, \llbracket x \rrbracket^{w}\right) \wedge$ there is some maximal $\lesssim g_{\text {want }}(e)$ chain $S$ such that $\llbracket p \rrbracket^{w^{\prime}}=1$ for every $\lesssim g_{\text {want }}(e)$-minimal world $w^{\prime}$ in $\left.S \cap \bigcap f_{\text {want }}(e)\right]$

The semantics in (i) treats 'want' as quantifying over the "bouletically best" worlds in the modal base given some way of resolving incomparabilities in the subject's desires; the necessity semantics in (60) for 'hope', in contrast, quantifies over the minimal worlds in the modal base given every way of resolving incomparabilities in the subject's desires. These semantics predict the consistency of irresolvable dilemmas expressed with 'want' but not with 'hope' - parallel to the cases of 'ought' and 'must' discussed by Swanson. What the Swanson-style approach captures via incomparability-sensitive weakening of the truth conditions relative to a constant ordering source, the approach in the main text captures via restrictions (or lack thereof) on ordering sources and intra-sentential shifts. Connections with dilemmas and weak/strong necessity modals may provide fruitful avenues to explore (see also Silk 2012, 2018; Rubinstein 2014).
} 
in $\operatorname{SoM}(e)$, the representation of the subject's state of mind. ${ }^{21}$ Subjunctive-selection with emotive factives follows from the proposed analysis of mood and independently attested features of their semantics.

\subsubsection{Indicative-selection with dire}

Let's turn to applying the state-of-mind account of mood to speech-act verbs. The difference in the general pattern of explanation will be in the type of event described: Attitude verbs describe aspects of subjects' concrete states of mind; speech-act verbs describe aspects of concrete discourses. For an attitude event $e$, the informationalevaluative content of $e, \operatorname{SoM}(e)$, represents the subject's overall state of mind; for a discourse event $e$, the informational-evaluative content of $e, \operatorname{SoM}(e)$, represents the state of the discourse, i.e. the mutually presupposed information and priorities (Sect. 4.1). As previously, the task is to explain the mood-selection data in terms of this general assumption about discourse events and independently attested features of the verbs' semantics.

Perhaps the most straightforward case is dire 'say'. Dire takes a modal base $f_{\text {say }}(e)$ that represents the individual public presuppositions of the subject $x$ in the reported (possibly single-membered) discourse event $e$ (written $C G_{e_{x}}$ ), i.e. what she publicly treats as true for purposes of conversation. (As with croire, assume that the ordering source $g_{s a y}(e)$ and its analogue in the representation of context are empty; Sects. 4.1, 4.2.1.) As a speech-act verb, dire describes an aspect of a reported discourse $e$. The informational-evaluative content of $e$ - the "state of mind" characterizing it, $\operatorname{SoM}(e)$ - is the mutually presupposed information and priorities. Since one's individual public presuppositions in a discourse are a superset of the mutual public presuppositions, $C G_{e_{x}} \supseteq C G_{e}$, the presupposition of [+_ind] is invariably satisfied: $\left(\bigcap f_{\text {say }}(e), \lesssim g_{\text {say }}(e)\right) \unlhd \operatorname{SoM}(e)$, since $f_{\text {say }}(e) \supseteq C G_{e}$. Hence dire selects indicative.

\subsubsection{Indicative-selection with promettre versus subjunctive-selection with ordonner}

Finally, let's consider commissives like promettre 'promise', which select indicative, and directives like ordonner 'order', which select subjunctive. Commissives and directives are speech-act verbs: they describe aspects of discourse events $e$; they report-and in special cases perform - commissive and directive speech acts. So, as above, the content of the events they describe, $\operatorname{SoM}(e)$, is the presuppositions and priorities of the reported discourse. What should we say about the verbs' modal backgrounds and their relations to these contextual parameters?

Let's start with ordonner. The ordering source $g_{\text {ord }}(e)$ represents the subject's commitments about the obligations imposed on the object by the subject in the reported discourse event $e$-roughly put, the object's "subject-dependent priorities" in $e$. An

\footnotetext{
21 We can leave open how exactly the modal bases of emotive factives are identified. Following von Fintel (1999), a plausible constraint is that $\bigcap f_{E}(e)$ properly include $\bigcap D O X_{e}$. It's worth flagging that although emotive factives in French are often treated as requiring subjunctive (e.g., Schlenker 2005), some speakers report finding optional uses of indicative to be possible (e.g., Farkas 2003). I leave open how the account might be modified for the latter dialect or stage of French.
} 
initial idea might be to treat the modal base $f_{\text {ord }}(e)$ as the common ground information in the reported discourse event $e$. This would capture the anomalousness of directive utterances enjoining $p$ in contexts where $p$ is presupposed:

[Context: Addressee is sitting down.]

a. \#Sit down!

b. \#I order you to sit down.

On the hypothesis that $f_{\text {ord }}(e)=C G_{e}$, such examples violate the diversity condition since $\bigcap C G_{e} \subseteq p$-hence the infelicity.

However, it won't do simply to identify the predicate's modal base with the reported common ground. As noted in Sect. 3.2, directive utterances are anomalous when coupled with denials that they will be satisfied; indeed directive utterances are compatible with acceptance that they will be satisfied:

a. Leave! - \#even though (I know) you won't.

b. I order you to leave! — \#even though (I know) you won't.

(cf. Portner 2009: 190)

(65) We didn't call for backup because I ordered Alice and Bert to come to the scene.

(66) [Context: After opening an email from your boss, you say to your project team:]

The boss regrets that we'll miss the party but he orders us to finish the project tonight.

(67) I know you will clean the barracks because I order you to.

Though obligations can go unfulfilled, discourse participants appear to assume otherwise for purposes of conversation when accepting directive utterances. Identifying $f_{\text {ord }}(e)$ with $C G_{e}$ incorrectly predicts (65)-(67) to violate the diversity condition and hence be infelicitous like (63).

A natural response is to take up the Heim-style strategy for $f_{\text {want }}$ from Sect. 4.2.3 and treat the modal base $f_{\text {ord }}(e)$ as representing what is presupposed to be the case no matter what the subject has ordered the object to do (cf. footnote 19). This captures the felicity of examples such as (65)-(67). In (67), given that the addressee's cleaning the barracks depends at least partly on one's order, both clean-worlds and $\neg$ cleanworlds are included in $\bigcap f_{\text {ord }}(e)$, and the diversity condition isn't violated. Ordering $p$ is compatible with a presupposition that $p$ if one's orders constitute the basis for the presupposition that $p$. Examples such as (63) are still predicted infelicitous. If the addressee already satisfies $p$ or has committed to satisfying $p$ for independent reasons, it won't be the case that $p$ is true independent of one's orders; so, the modal base will imply $p$, violating diversity. The anomalousness of Bill's order in (68) seems due, in part, to the suggestion that our acceptance that Mary will bring the dessert is to be grounded in his ordering her to do so rather than in Mary's prior commitment. 
(68) Mary: I will bring dessert to the party later.

Bill: $\quad$ Yes. I order you to bring dessert.

Mary: I just that said I will! Sheesh.

Given that the presupposition that Mary will bring dessert is independent of Bill's order, $\bigcap f_{\text {ord }}(e) \subseteq$ dessert and diversity is violated.

These observations about the modal base $f_{\text {ord }}$ predict subjunctive-selection with ordonner. What is presupposed to be the case no matter what has been ordered is a superset of what is presupposed to be the case. So, parallel to the case of vouloir, $\bigcap f_{\text {ord }}(e) \nsubseteq \bigcap C G_{e}$ and the presupposition of [+_ind] is violated-hence subjunctive-selection with directives such as ordonner.

Now turn to commissives. The ordering source $g_{\text {prom }}(e)$ consists of the propositions which the subject has committed to the object to being/making true-roughly put, the subject's "subject-dependent priorities" to the object in the reported discourse event $e$. Above we observed a parallel between ordonner 'order' and vouloir 'want' in their modal bases and resulting mood-selection properties. An attractive hypothesis is to treat the mood-selection contrast between directives and commissives parallel to the mood-selection contrast between vouloir and espérer. The modal base $f_{\text {hope }}(e)$ is identified with the subject's beliefs $D O X_{e}$, a subset of which constitutes the modal base $f_{\text {want }}(e)$; so too, the thought goes, the modal base $f_{\text {prom }}(e)$ is identified with the presuppositions of the reported discourse $C G_{e}$, a subset of which constitutes the modal base $f_{\text {ord }}(e)$.

As with directives, making a promise is anomalous when coupled with an assertion or assumption that it won't be satisfied; (69)-(70), like (64), are infelicitous.

(69) I promise to bring dessert — \#even though I won't.

(70) [Context: It's mutually presupposed that there is no way Mary will be able to come to the party later. Mary says:]

\#I promise to come to the party later.

Promising $p$ generally presupposes that $p$ is possible. Yet whereas ordering $p$ is compatible with presupposing $p$ as long as $p$ 's truth is assumed to depend on one's order, as in (65)-(67), promising $p$ seems to require that $p$ not be presupposed. Although promising $p$ can be coupled with an assertion that $p$, as in (71)-(72), such examples still seem to suggest that $\neg p$ is a live possibility in the discourse. The function of the promises in (71)-(72) is plausibly to reinforce a commitment to something that may be open to doubt.

(71) I will bring dessert to the party later. I promise.

(72) Sue (to Bill):I will bring drinks to the party later. Mary will bring dessert. Mary: $\quad$ Yes. I promise.

Promising $p$ given a manifest presupposition that $p$ is generally anomalous, even if the presupposition that $p$ depends on what one has promised. Using 'promise' in (75a) is dispreferred as a reminder of something accepted in the common ground due to an 
earlier commitment. (74a) is odd, even if it would be generally felicitous for one to presuppose $p$ in light of a future-tense assertion that $p$, as in (74b). ${ }^{22}$

(73) [Context: You are waiting to hear from your friend Sue about whether she will get off work in time to watch your children. After seeing a message from Sue, you say to your partner:]

?Sue is glad we won't need a babysitter since she promises to be here by 5 .

[Context: The party is starting soon, and your team can't go until you finish your part of the report. You say:]

a. ?I'm glad we won't be late since I promise to finish the report in 10 minutes.

b. I'm glad we won't be late since I'll have the report finished in 10 minutes.

[Context: Earlier you promised your partner you that would be home tonight by 5 p.m. Your partner said 'okay', and your reliability isn't doubted. Before heading out for some errands, you say:]

a. ?I promise to be home by 5 .

b. I'll see you at 5 .

Identifying $f_{\text {prom }}(e)$ with the reported common ground $C G_{e}$ captures this: the diversity condition requires that there be some $\neg p$-worlds in $\bigcap f_{\text {prom }}(e)=\bigcap C G_{e}$, which contrasts with the contextual assumption that $p$-hence the infelicity.

The above examples support treating the modal base $f_{\text {prom }}$ as representing the common ground information in the reported discourse. Our evidence with directives that the set of modal-base worlds isn't included in $\bigcap C G_{e}$ - the information characterizing the reported event $e$-doesn't carry over to commissives. The presupposition of $\left[+\_\right.$ind $]$is satisfied, and promettre selects indicative.

\subsection{Selection and grammaticalization}

The proposed state-of-mind account follows $\mathrm{P} \& \mathrm{R}$ and various others in the literature in providing a semantic analysis of mood. Mood marking is treated in terms of a relation between the semantics of the predicates and mood features in context, rather than simply in terms of the semantics of the predicates (as in e.g. Farkas 1992; Giannakidou 1999). Distinguishing the contribution of mood features helps capture cases of mood choice_- predicates which can take indicative or subjunctive-without positing distinct lexical entries. Yet it raises a potential worry about explanatoriness in cases of selection. In Sect. 3 we saw that P\&R treat vouloir and ordonner as lexically associated with $\left[+\_s b j v\right]$ in order to explain why the predicates must take subjunctive even in contexts where the contextual commitment $P R$ presupposition is satisfied. In light of parallel examples with indicative-selecting predicates - examples where indicative

\footnotetext{
22 The data contrasting orders and promisings are supported by preliminary results from an acceptability judgment task via Amazon Mechanical Turk. Fifteen participants were asked how natural they found the target sentences, on a scale from 1 ("completely unnatural") to 7 ("completely natural"). Participants reported (65)-(66) with 'order' as natural—for (65) the average rating was 5.67 (SEM =.27); for (66) the average rating was 5.27 (SEM $=.38)$. $(73)$ with 'promise' was reported as relatively marginal, average rating $3.93(\mathrm{SEM}=.56)$. Thanks to a referee.
} 
is required even though $\mathrm{P} \& \mathrm{R}$ 's posited presupposition of $\left[+\_\right.$ind $]$isn't satisfied-I noted that $P \& R$ might revise their account by positing grammaticalized indicative as well. Grammaticalizing mood selection more generally in this way weakens the explanatoriness of a semantic analysis of mood based on contextual commitment ${ }_{P R}$.

The state-of-mind account developed in this section captures the mood-selection properties of the predicates in question without positing lexical association with mood-licensing features. The mood-selection properties of doxastic attitude verbs such as croire, fiction verbs, desideratives such as vouloir and espérer, emotive factives, and various types of speech-act verbs are derived from the analysis of mood in Sect. 4.1 along with independently attested features of the predicates' semantics, general assumptions about the informational-evaluative contents of attitude/discourse events, and general principles of interpretation (Maximize Presupposition!, diversity condition). This isn't to say that there is no grammaticalization in matters of mood selection. But, other things equal, we should prefer an account which derives the moodselection properties without stipulating them in the grammar or lexical semantics.

\subsection{Modal adjectives}

This paper has focused on puzzles of mood selection with speech-act and attitude verbs. An important contribution of P\&R's discussion is to introduce data with modal adjectives (possible, probable, nécessaire) into theorizing about mood. Modal adjectives ostensibly afford a fruitful test case for P\&R's approach: since what modal backgrounds are relevant for interpreting the adjectives depends on context, pragmatic correlates of mood choice such as commitment of speaker, addressee, etc. might seem more apparent. ${ }^{23}$ Yet, as noted in Sect. 1, it is precisely because of this contextual dependence that I have set the adjectives aside (see footnote 3). Questions about the context-sensitivity and modal backgrounds of epistemic and normative/evaluative readings of modals are fraught. Ongoing contextualism/relativism/expressivism debates highlight independently contentious issues regarding how the apparent context-sensitivity is to be implemented, what modal backgrounds are "relevant" in particular cases, and in some cases what the data even are. A principal point of contention is what the modal background represents as a function of context-for instance, for certain epistemic readings, whether it represents the speaker's information (evidence, knowledge, etc.), the pooled information of a relevant group, or the discourse common ground. How graded modal expressions are to be analyzed in classic ordering semantics/premise semantics, and whether they can be analyzed in the classic framework at all, remains to be seen. Settling on such issues is precisely what would be needed for developing and evaluating a state-of-mind account.

That said, it may be useful to outline how the state-of-mind account in this section might be applied to certain modal adjectives. I focus on nécessaire 'necessary' and possible 'possible', given the additional complications mentioned above regarding the modal backgrounds of gradable epistemic adjectives such as probable 'probable'. More thorough investigation of other adjectives, interpretive differences in cases of

23 Thanks to a referee for reinforcing the dialectical role of P\&R's modal adjective cases. 
mood choice, and interactions with broader work on context-sensitivity and modal expressions is needed. Final assessment of the modal adjective data and its role in adjudicating among theories of mood must await future research.

Consider subjunctive-selection with nécessaire and possible:

Il est possible que cet échantillon soit dissout dans l'eau.

it is possible that this sample is.SBJV dissolved in the water

Il est possible/nécessaire que vous preniez le train A.

it is possible/necessary that you take.SBJV the train A

(cf. Portner and Rubinstein 2012: exs. (15), (34))

Nécessaire and possible take a circumstantial modal base representing a set of circumstances/facts, and in priority-based interpretations an ordering source representing the relevant type of priority. (P\&R follow Rubinstein 2012 in treating nécessaire as lexically specifying a priority interpretation, often teleological.) The purely circumstantial reading of possible in (76) says that the sample's dissolving is possible given the relevant circumstances $f_{c}(e)$. The teleological readings in (77) say that your taking the A-train is possible/necessary in light of some contextually relevant goals $g_{c}(e)$ (say, the goals of the individuals in $e$ ), given the circumstances $f_{c}(e)$.

As noted in Sect. 4.1, a key feature of Hacquard's $(2006,2009,2010)$ developments of the event-relativity of modals is that speech-act/attitude/epistemic predicates are distinguished from other predicates in being conceptualized as describing events with content; events as described by root/non-epistemic modals are conceptualized as in general lacking informational content. ${ }^{24}$ If this is right, subjunctive-selection for modal adjectives such as nécessaire and possible taking circumstantial modal bases follows straightaway: $S o M$ is a partial function from contentful events. The presupposition of [+_ind], $\left(\bigcap f_{c}(e), \lesssim g_{c}(e)\right) \unlhd \operatorname{SoM}(e)$, isn't satisfied since $\operatorname{SoM}(e)$ is undefined. Hence subjunctive must be used.

P\&R appeal to the modal adjective cases in their arguments against the "protostandard analysis" of mood. For instance, subjunctive-selection in purely circumstantial readings such as (76) is unexpected if subjunctive-selection is analyzed in terms of taking a non-empty ordering source or having a comparative semantics. Yet P\&R themselves ultimately appeal to grammaticalized mood for possible (and probable) (2012: 477, 480-481). Though P\&R don't mention grammaticalization with nécessaire, it seems they would need to appeal to grammaticalized subjunctive for nécessaire as well. Nécessaire, like possible, selects subjunctive even if the interlocutors are contextually committed to the circumstantial/priority-based modal backgrounds. Although there are certainly contexts where interlocutors aren't collectively committed to the relevant information or priorities, it is perhaps surprising that such contexts would be conceptualized as prototypical in the use of the adjectives. At minimum one might expect some languages to treat uses of agreement and endorsement as prototypical. Yet modal expressions of necessity/possibility typically select subjunctive across languages. The state-of-mind treatment of subjunctive-selection with nécessaire and possible outlined above avoids invoking grammaticalized mood. Subjunctive-selection falls out of the

24 Though see Sect. 6 on this as a possible source of crosslinguistic variation. 
proposed account of mood and a Hacquard-style treatment of the event-relativity of modal backgrounds.

It's worth noting that a state-of-mind account needn't be hostage to a Hacquardinspired treatment of SoM as undefined for events as described by circumstantial modal adjectives. Suppose that for such events one treats $\operatorname{SoM}(e)$ as representing the set of facts in $e$. Uses of nécessaire 'necessary' and possible 'possible' are compatible with the truth or acceptance of the embedded proposition $p$; the truth of $p$ can even be specified as among the relevant facts, as in (78).

(78) C'est bien que cet échantillon soit dissous parce qu'il est nécessaire it's good that this sample is dissolved because it is necessary qu'il soit dissous pour que nous puissions obtenir la subvention. that it is.SBJV dissolved for that we can get the grant 'It's good that this sample dissolves because it's necessary for it to dissolve in order for us to get the grant.'

(cf. Portner and Rubinstein 2012: ex. (16))

(79) Il est possible que nous prenions le train A. Nous allons donc arriver it is possible that we take.SBJV the train A we will therefore arrive au concert à temps.

to the concert on time

'It's possible for us to take the A-train. So, we'll get to the concert on time.'

To avoid incorrectly predicting that such examples violate the diversity condition, the modal bases $f_{c}(e)$ for the priority-based readings can be treated as some subset of the set of circumstances in $e$ (say, the set of facts that hold no matter what the priorities are in $e$; cf. Frank 1996). So, $\bigcap f_{c}(e)$ isn't included in the informational content characterizing $e, \operatorname{SoM}(e)$, and the presupposition of $\left[+\_\right.$ind $]$is violated. Subjunctive-selection with purely circumstantial uses such as (76) might then be understood as cases of grammaticalized mood. Many modal adjectives are like possible — and unlike attitude/speech-act verbs (or nécessaire, if Rubinstein 2012 is right) in being able to receive both priority-based and non-priority-based interpretations, depending on the context. Given this flexibility it is perhaps not unexpected that in cases where grammaticalization occurs, such adjectives should "generalize to the weakest case" and become lexically associated with the unmarked mood feature, i.e. $\left[+\_s b j v\right] .^{25}$

\footnotetext{
25 It's common in premise semantics for graded modality to treat expressions such as probable as taking an ordering source determining the graded interpretation. A treatment of uses of probable with subjunctive could then proceed parallel to the alternative treatment of nécessaire/possible given above. Uses of probable are compatible with the truth or acceptance of the embedded proposition, as in (a); so, given the diversity condition, the modal base $\bigcap f_{c}(e)$ must be a superset of the contextual information $\operatorname{SoM}(e)$, violating the presupposition of $\left[+\_i n d\right]$ :

(a) 11 est probable que des amendements soient même présentés plus tard aujourd'hui au comité. Quelqu'un décidera s'ils sont recevables ou non, et nous voterons ensuite.

'It is probable that amendments will be.SBJV introduced even later today in committee. Someone will rule whether they are in order or not, and we will vote.'
}

(www.noscommunes.ca/DocumentViewer/fr/40-3/chambre/seance-34/debats) 


\section{Literature comparisons}

We began in Sect. 1 by introducing accounts of mood which give a notion of commitment a fundamental explanatory role. Sections 2-4 focused on critically examining P\&R's specific "contextual commitment" account of mood selection in French and comparing it to the proposed state-of-mind account. Indicative-selecting predicates "presuppose commitment," according to P\&R's qualitative definition of commitment, in the sense of presupposing (roughly) that every individual argument of the predicate is disposed to defend the propositions in the predicate's modal base and ordering source as reasonable in any relevant conversation. The strategy of the state-of-mind approach from Sect. 4, in contrast, is to explain mood selection in terms of whether the formal relation between the predicate's modal backgrounds and an overall state of mind represents a relation of commitment: Indicative-selecting predicates in French "presuppose commitment" in the sense of presupposing that the modal state determined by the predicate's semantics is "live" from the perspective of the modal state representing the (attitude/discourse) event $e$ described by the predicate. Sections 4.24.3 argued that this account provides a more explanatory treatment of the puzzle cases from Sects. 1-3. Now that the state-of-mind approach is on the table, briefly comparing it to several other broadly commitment-based accounts may help further situate it in the literature. I leave more detailed comparisons and discussion of other types of accounts for future research.

A prominent approach is to analyze mood in terms of epistemic commitment to the complement. To a first approximation, indicative-selecting predicates are treated as implying that the speaker/subject takes the complement to be true (Noonan 1985; Palmer 1986; Farkas 1992; Giannakidou 1999; Marques 2009; Siegel 2009), or bears some suitably strong epistemic attitude toward the complement (Smirnova 2011). Persistent challenges for these accounts include subjunctive-selection with emotive factives (though see Siegel 2009), indicative-selection with fiction verbs and commissives, and indicative-selection with 'hope'.

Footnote 25 continued

Although probable often takes subjunctive, $P \& R$ observe that there are contexts where it can take indicative. P\&R's account is less than compelling; apparent differences in interpretation between uses with subjunctive and indicative are treated by appealing to multiple lexical entries, grammaticalized mood, and an unanalyzed distinction between "subjective opinion" and "objective data" (2012: 474-475, 480). Theoretical worries aside, empirical difficulties include indicative-taking descriptive uses of probable which don't present the speaker as accepting the relevant information, as in (b). (Half of the participants in a translation task conducted via Amazon Mechanical Turk used indicative.) The speakers in such examples are committed to thinking that the assumed modal background correctly represents the information in the filing cabinet-they have "sense-(ii)" commitment in the sense of Sect. 3.3; they lack commitment $P R$ (cf. footnote 12).

(b) [Context: We're standing before a locked filing cabinet. None of us has had access to the information in it, but we know it contains the police's evidence about Fischer's murder and narrows down the set of suspects. We're betting on the chances that one of us may have killed Fischer according to the information in the filing cabinet. You, who we all know is innocent, say:]

Il est probable que je l'ai fait.

it is probable that I it have.IND did

'It's probable that I did it.'

(cf. Kratzer 2012: 98-99)

I leave theorizing about a state-of-mind treatment of mood choice with probable for future research. 
Take, for instance, Giannakidou's appeal to veridicality (Sect. 3.3). Though a notion of veridicality might initially seem to be associated with notions of realis or truth, in Giannakidou's account it ends up amounting essentially to entailment: indicativeselecting predicates are treated as predicates which entail the truth of their complement in "some epistemic model." 26 The challenge is to provide an independent account of what demarcates the class of epistemic models. What conceptually unifies sets of worlds representing what someone says, believes, or dreams, and what distinguishes them from sets of worlds representing what someone desires or orders? Why is implication by sets of worlds in the former class sufficient for "veridicality," but implication by sets of worlds in the latter class is not? Why would fiction verbs, which typically don't describe reality and whose complements typically aren't regarded as true by the subject, be systematically conceptualized as "veridical," while directive verbs, which report utterances that are incompatible with denials of their complements, be systematically conceptualized as "non-veridical"?

Understanding indicative-selection in terms of states of mind captures intuitions motivating epistemic-commitment accounts. Bearing a certain epistemic attitude toward the complement is neither necessary nor sufficient for indicative-selection in French. What is important is rather that the modal state determined by the predicate's semantics be included in the modal state representing the event described by the predicate. This view carves out a role for both doxastic and evaluative commitments in mood selection. And it allows for-indeed predicts-indicative-selecting predicates which lack doxastic commitment to the complement (e.g., espérer), and subjunctiveselecting predicates which imply doxastic commitment (e.g., emotive factives).

Schlenker's (2005) account of mood selection in French bears important similarities to the state-of-mind account developed in Sect. 4. On Schlenker's account, indicative mood presupposes that the evaluation world is in the "context set" of a relevant thought event or speech event. The state-of-mind approach follows Schlenker in giving a generalized notion of context a fundamentally explanatory role. However, first, on Schlenker's account the grammar leaves open what event determines the context set relevant for satisfying the indicative presupposition. It might be the event described by the embedding predicate (in which case the relevant context set is the verb's modal base) or the event described by the utterance (in which case the relevant context set is the discourse context set). This view fails to explain why mood selection in French seems to be systematically determined by the attitudes of the subject rather than the speaker-e.g., why vouloir, directives, etc. cannot select indicative even if the speaker is publicly committed to the complement. Second, Schlenker treats mood selection as sensitive to a context set, which is conceptualized as a body of background information for an assertive act. The account in Sect. 4 treats mood selection as sensitive to relevant information and priorities (norms, preferences, etc.). Mood selection is analyzed in terms of representations of overall states of mind and the informational-evaluative contents of events.

\footnotetext{
26 To capture subjunctive-selection with various modal predicates, Giannakidou posits that all readings of modals (including epistemic possibility/necessity modals and circumstantial modals) take non-empty ordering sources (see also Giannakidou 2016; Giannakidou and Mari 2016). Our provisional treatment in Sect. 4.4 of subjunctive with certain modal adjectives doesn't require such a commitment.
} 
P\&R present their account as a foil to what they call the "proto-standard" analysis of mood (Sect. 2). Accounts in this tradition demarcate subjunctive-selecting predicates as those predicates which take a non-trivial ordering source. As P\&R argue, indicative-selecting desideratives such as 'hope' and commissives pose challenges for these accounts. Though the state-of-mind account doesn't explain mood selection fundamentally in terms of having a comparative semantics, our appeal to a general diversity condition on modal bases suggests that ordering sources may have an indirect effect on mood selection. The diversity condition requires that any non-empty ordering source non-trivially distinguish among worlds in the modal base with respect to the embedded proposition $p$. For any predicate that takes a non-empty ordering source there must be $p$-worlds and $\neg p$-worlds in the modal base $\bigcap f(e)$. Our account predicts (inter alia) that, for any predicate $P$ in French that takes a non-empty ordering source: if $P$ selects indicative, then uses of $P$ are incompatible with assuming that the informational content of the event $e$ described by $P$ (e.g., the subject's beliefs, the reported discourse common ground) implies $p$. On the flip side, if uses of $P$ necessarily assume that the informational content of the event described by $P$ implies the embedded proposition $P$, then $P$ selects subjunctive. This captures indicative-selection with espérer 'hope' and subjunctive-selection with emotive factives, respectively.

\section{Conclusion and outlook}

This paper has developed an account of mood selection with attitude predicates in French. The guiding idea is to analyze mood in terms of a relation between a predicate's semantics and an overall state of mind: Indicative mood in French presupposes that the modal evaluation of the clause relies only on worlds and evaluative relations that are live from the perspective of the modal state representing the "state of mind" characterizing the event $e$ described by the embedding predicate $P$-formally, that the preordered set $\left(\bigcap f_{P}(e), \lesssim_{g_{P}(e)}\right)$ determined by $P$ 's semantics is included in the preordered set representing the informational-evaluative content of $e$, such as a subject's overall doxastic-affective state or the mutually presupposed information and priorities of a discourse. The aim has been to derive patterns of mood selection from (i) the proposed analysis of mood, (ii) a general assumption about the informationalevaluative content of discourse events and attitude events, (iii) independent linguistic evidence about the predicates' semantics and specific modal backgrounds, and (iv) general principles of interpretation. I argued that the account captures various core cases of mood selection. These cases include indicative-selection with croire, dire, and fiction verbs, subjunctive-selection with emotive factives (in contrast to non-emotive factives), indicative-selection with espérer versus subjunctive-selection with vouloir, and indicative-selection with promettre versus subjunctive-selection with ordonner. The proposed account captures intuitions motivating certain previous approaches to mood selection, while improving in empirical coverage and explanatory power.

Our discussion has been limited. I only considered a single language: French. And I focused on mood marking in the complements of attitude and speech-act predicates, in particular on cases of mood selection, or predicates which require a particular mood in the complement clause. It is worth investigating how the proposed account may be 
applied more generally-e.g., to mood marking in main clauses and mood switching under negation and in questions; to cases of mood choice and interpretive differences among examples with predicates that optionally take indicative or subjunctive; and to mood selection/choice in other Romance and non-Romance languages. The approach in this paper may provide a framework for addressing such broader issues. Consider issues of crosslinguistic variation. The explanatory components in (i)-(iv) above elucidate lines of inquiry for investigating mood crosslinguistically:

(i) For different languages: In the presupposition of the indicative feature, which event is SoM sensitive to, ${ }^{27}$ and what is the required logical relation to the predicate's modal backgrounds? Does the indicative presupposition concern the content of the event described by the local embedding predicate, as in French? Or does it concern the content of the evaluation/speech event? Or does the semantics of [+_ind] itself leave the option open? Is the modal state determined by SoM specified as including the modal state determined by the predicate's modal backgrounds? (ii) How do speakers conceptualize the informational-evaluative content, if any, of different types of events? Do speakers generally conceptualize the distinction between content-bearing versus non-content-bearing events in terms of a distinction between attitude/discourse events versus other events-or, linguistically put, in terms of the distinction between events as described by attitude/speechact/epistemic predicates versus events as described by other predicates? Are the contents of attitude events and discourse events generally represented in the same sort of way?

(iii) Are there interesting crosslinguistic generalizations about the sorts of pairs of modal backgrounds that are lexicalized in attitude/speech-act predicates, and about the relation between these lexicalized backgrounds and representations of context and overall states of mind (e.g. desiderative/doxastic predicates with modal backgrounds invoking all versus a particular subset of the subject's beliefs/desires; speech-act predicates with modal backgrounds invoking individual versus mutual discourse commitments, or individual commitments of subject versus object)?

(iv) What is the crosslinguistic status of interpretive principles such as Maximize Presupposition! or non-vacuity conditions such as the diversity condition on modal bases? Are other relevant interpretive principles at play in other languages? Are there interesting crosslinguistic relations between such principles and patterns of optional versus obligatory indicative, or the determination of predicates' specific modal backgrounds?

Investigating these components and how they interact may bring into relief interesting crosslinguistic generalizations and sources of crosslinguistic variation.

The prospects for the specific account of mood in this paper remain to be seen. I hope our discussion has illustrated the fruitfulness of the general state-of-mind frameworkthe proposed semantic approach to mood, pattern of explanation, and treatment of

27 Suggestively, and theory-ladenly, put: "Is the presupposition of [+_ind] required to be locally satisfied (satisfied in the context representing the local state of mind)? Or required to be globally satisfied? Or is how it is satisfied sensitive to contextual (and perhaps lexically specific) factors?" 
context and content in terms of overall states of mind - for theorizing about issues of mood and modality.

Acknowledgements Thanks to three anonymous referees, the copy-editor, and the editors for comments. This research has benefited from the support of an AHRC Early Career Research Grant (AH/N001877/1).

Open Access This article is distributed under the terms of the Creative Commons Attribution 4.0 International License (http://creativecommons.org/licenses/by/4.0/), which permits unrestricted use, distribution, and reproduction in any medium, provided you give appropriate credit to the original author(s) and the source, provide a link to the Creative Commons license, and indicate if changes were made.

\section{References}

Alston, W.P. 1988. The deontological conception of epistemic justification. Philosophical Perspectives 2: 257-299.

Anand, P., and V. Hacquard. 2013. Epistemics and attitudes. Semantics and Pragmatics 6: 1-59.

Anand, P., and V. Hacquard. 2014. Factivity, belief and discourse. In The art and craft of semantics: A festschrift for Irene Heim, vol. 1, ed. L. Crnič and U. Sauerland, 69-90. Cambridge, MA: MITWPL.

Bennett, J. 1990. Why is belief involuntary? Analysis 50: 87-107.

Bittner, M. 2011. Time and modality without tenses or modals. In Tense across languages, ed. M. Rathert and R. Musan, 147-188. Tübingen: Niemeyer.

Błaszczak, J., A. Giannakidou, D. Klimek-Jankowska, and K. Migdalski (eds.). 2016. Mood, aspect, modality revisited: New answers to old questions. Chicago, IL: The University of Chicago Press.

Bolinger, D. 1968. Post-posed main phrases: An English rule for the Romance subjunctive. Canadian Journal of Linguistics 14: 3-30.

Charlow, N. 2011. Practical language: Its meaning and use. PhD thesis, University of Michigan.

Clark, H.H. 1996. Using language. Cambridge: Cambridge University Press.

Condoravdi, C. 2002. Temporal interpretation of modals: Modals for the present and for the past. In The construction of meaning, ed. D.I. Beaver, L.D.C. Martínez, B.Z. Clark, and S. Kaufmann, 59-88. Stanford, CA: CSLI Publications.

Farkas, D. 1992. On the semantics of subjunctive complements. In Romance languages and modern linguistic theory, ed. P. Hirschbühler and E. Koerner, 69-104. Amsterdam: John Benjamins.

Farkas, D. 2003. Assertion, belief and mood choice. Paper presented at ESSLI, Conditional and unconditional modality workshop, September 2003, Vienna.

Farkas, D.F., and K.B. Bruce. 2010. On reacting to assertions and polar questions. Journal of Semantics 27: 81-118.

von Fintel, K. 1999. NPI licensing, Strawson entailment, and context dependency. Journal of Semantics 16: 97-148.

von Fintel, K., and A.S. Gillies. 2010. Must... stay... strong!. Natural Language Semantics 18: 351-383.

Frank, A. 1996. Context dependence in modal constructions. PhD thesis, University of Stuttgart.

Giannakidou, A. 1994. The semantic licensing of NPIs and the modern Greek subjunctive. Language and cognition 4: Yearbook of the research group for theoretical and experimental linguistics, 55-68. Groningen: University of Groningen.

Giannakidou, A. 1995. Subjunctive, habituality, and negative polarity items. In Proceedings of SALT 5, ed. M. Simons and T. Galloway, 94-111. Ithaca, NY: CLC Publications.

Giannakidou, A. 1997. The landscape of polarity items. PhD thesis, University of Groningen.

Giannakidou, A. 1999. Affective dependencies. Linguistics and Philosophy 22: 367-421.

Giannakidou, A. 2016. Evaluative subjunctive and nonveridicality. In Błaszczak et al. (2016), 177-217.

Giannakidou, A., and A. Mari. 2016. Epistemic future and epistemic MUST: Nonveridicality, evidence, and partial knowledge. In Błaszczak et al. (2016) 75-117.

Gibbard, A. 1990. Wise choices, apt feelings: A theory of normative judgment. Cambridge: Harvard University Press.

Gibbard, A. 2005. Truth and correct belief. Philosophical Issues 15: 338-350.

Ginzburg, J. 2012. The interactive stance: Meaning for conversation. Oxford: Oxford University Press.

Giorgi, A., and F. Pianesi. 1997. Tense and aspect: From semantics to morphosyntax. Oxford: Oxford University Press. 
Goble, L. 2013. Prima facie norms, normative conflicts, and dilemmas. In Handbook of deontic logic and normative systems, vol. 1, ed. D. Gabbay, J. Horty, X. Parent, R. van der Mayden, and L. van der Torre, 241-352. London: College Publications.

Gowans, C.W. (ed.). 1987. Moral dilemmas. New York, NY: Oxford University Press.

Grant, C. 1949. Promises. Mind 58: 359-366.

Gunlogson, C. 2001. True to form: Rising and falling declaratives as questions in English. PhD thesis, UC Santa Cruz.

Gunlogson, C. 2008. A question of commitment. Belgian Journal of Linguistics 22: 101-136.

Hacquard, V. 2006. Aspects of modality. PhD thesis, MIT.

Hacquard, V. 2009. On the interaction of aspect and modal auxiliaries. Linguistics and Philosophy 32 (3): 279-315.

Hacquard, V. 2010. On the event relativity of modal auxiliaries. Natural Language Semantics 18 (1): $79-114$.

Harnish, R.M. 1990. Speech acts and intentionality. In Speech acts, meaning, and intentions: Critical approaches to the philosophy of John R. Searle, ed. A. Burkhardt, 169-193. New York, NY: de Gruyter.

Heim, I. 1991. Articles and definiteness. In Semantics: An international handbook of contemporary research, ed. A. von Stechow and D. Wunderlich, 487-535. Berlin: de Gruyter.

Heim, I. 1992. Presupposition projection and the semantics of attitude verbs. Journal of Semantics 9: 183-221.

Iatridou, S. 2000. The grammatical ingredients of counterfactuality. Linguistic Inquiry 31 (2): 231-270.

Kratzer, A. 1981. The notional category of modality. In Words, worlds, and contexts: New approaches in word semantics, ed. H.J. Eikmeyer, and H. Rieser, 38-74. Berlin: de Gruyter.

Kratzer, A. 1991. Modality/Conditionals. In Semantics: An international handbook of contemporary research, ed. A. von Stechow, and D. Wunderlich, 639-656. New York, NY: de Gruyter.

Kratzer, A. 2012. Modals and conditionals: New and revised perspectives. New York, NY: Oxford University Press.

Lassiter, D. 2011. Measurement and modality: The scalar basis of modal semantics. PhD thesis, New York University.

Lassiter, D. 2015. Epistemic comparison, models of uncertainty, and the disjunction puzzle. Journal of Semantics 32: 649-684.

Lauer, S. 2013. Towards a dynamic pragmatics. PhD thesis, Stanford University.

Lewis, D. 1979. A problem about permission. In Essays in honour of Jaakko Hintikka, ed. E. Saarinen, R. Hilpinen, I. Niiniluoto, and M. Hintikka, 163-175. Dordrecht: Reidel.

Lochbaum, K.E. 1998. A collaborative planning model of intentional structure. Computational Linguistics 24 (4): 525-572.

MacFarlane, J. 2014. Assessment sensitivity: Relative truth and its applications. Oxford: Clarendon Press.

Makinson, D. 1993. Five faces of minimality. Studia Logica 52 (3): 339-379.

Malamud, S.A., and T. Stephenson. 2015. Three ways to avoid commitments: Declarative force modifiers in the conversational scoreboard. Journal of Semantics 32: 275-311.

Marques, R. 2009. On the selection of mood in complement clauses. In Crosslinguistic semantics of tense, aspect, and modality, ed. L. Hogeweg, H. de Hoop, and A. Malchukov, 179-204. Amsterdam: John Benjamins.

Ninan, D. 2005. Two puzzles about deontic necessity. In New work on modality, ed. J. Gajewski, V. Hacquard, B. Nickel, and S. Yalcin, 149-178. Cambridge, MA: MITWPL.

Noonan, M. 1985. Complementation. In Language typology and syntactic description, vol. 2, Complex constructions, ed. T. Shopen, 52-150. Cambridge: Cambridge University Press.

Palmer, F. 1977. Modals and actuality. Journal of Linguistics 13: 1-23.

Palmer, F. 1986. Mood and modality. Cambridge: Cambridge University Press.

Piller, C. 2006. Content-related and attitude-related reasons for preferences. In Preferences and well-being, ed. S. Olsaretti, 155-182. Cambridge: Cambridge University Press.

Plantinga, A. 1993. Warrant: The current debate. Oxford: Oxford University Press.

Portner, P. 1997. The semantics of mood, complementation, and conversational force. Natural Language Semantics 5: 167-212.

Portner, P. 2004. The semantics of imperatives within a theory of clause types. In The Proceedings of SALT 14, ed. K. Watanabe and R. Young, 235-252. Ithaca, NY: CLC Publications.

Portner, P. 2007. Imperatives and modals. Natural Language Semantics 15 (4): 351-383.

Portner, P. 2009. Modality. Oxford: Oxford University Press. 
Portner, P., and A. Rubinstein. 2012. Mood and contextual commitment. In Proceedings of SALT 22, ed. A. Chereches, 461-487. Ithaca, NY: CLC Publications.

Portner, P., and A. Rubinstein. 2016. Extreme and non-extreme deontic modals. In Deontic modals, ed. N. Charlow and M. Chrisman, 256-282. New York, NY: Oxford University Press.

Quer, J. 2001. Interpreting mood. Probus 13: 81-111.

Roberts, C. 1996. Information structure: Towards an integrated theory of formal pragmatics. In OSU Working papers in linguistics, Vol. 49: Papers in semantics, ed. J.H. Yoon and A. Kathol. Columbus, OH: The Ohio State University.

Rubinstein, A. 2012. Roots of modality. PhD thesis, University of Massachusetts Amherst.

Rubinstein, A. 2014. On necessity and comparison. Pacific Philosophical Quarterly 95: 512-554.

Schlenker, P. 2005. The lazy Frenchman's approach to the subjunctive (Speculations on reference to worlds and semantic defaults in the analysis of mood). In Romance languages and linguistic theory 2003, ed. T. Geerts, I. van Ginneken, and H. Jacobs, 269-309. Amsterdam: John Benjamins.

Siegel, L. 2009. Mood selection in Romance and Balkan. Lingua 119: 1859-1882.

Silk, A. 2012. Modality, weights, and inconsistent premise sets. In Proceedings of SALT 22, ed. A. Chereches, 43-64. Ithaca, NY: CLC Publications.

Silk, A. 2016. Discourse contextualism: A framework for contextualist semantics and pragmatics. Oxford: Oxford University Press.

Silk, A. 2017. Modality, weights, and inconsistent premise sets. Journal of Semantics 34 (4): 683-707.

Silk, A. 2018. Weak and strong necessity modals. In Meaning, decision, and norms: Themes from the work of Allan Gibbard, eds. D. Plunkett and B. Dunaway. Ann Arbor: Michigan Publishing. http://goo.gl/ xY9roN

Sinnott-Armstrong, W. 1988. Moral dilemmas. Oxford: Basil Blackwell.

Smirnova, A. 2011. Evidentiality and mood: Grammatical expressions of epistemic modality in Bulgarian. $\mathrm{PhD}$ thesis, The Ohio State University.

Stalnaker, R. 1978. Assertion. Context and content: Essays on intentionality in speech and thought, 78-95. Oxford: Oxford University Press.

Stalnaker, R. 1984. Inquiry. Cambridge, MA: MIT Press.

Stalnaker, R. 2014. Context. New York, NY: Oxford University Press.

Starr, W. 2010. Conditionals, meaning, and mood. PhD thesis, Rutgers University.

Stephenson, T. 2007. Judge dependence, epistemic modals, and predicates of personal taste. Linguistics and Philosophy 30: 487-525.

Swanson, E. 2011. On the treatment of incomparability in ordering semantics and premise semantics. Journal of Philosophical Logic 40: 693-713.

Swanson, E. 2016. The application of constraint semantics to the language of subjective uncertainty. Journal of Philosophical Logic 45: 121-146.

Villalta, E. 2000. Spanish subjunctive clauses require ordered alternatives. In Semantics and Linguistic theory $(S A L T)$ 10, ed. B. Jackson and T. Matthews, 239-256. Ithaca, NY: CLC Publications.

Villalta, E. 2008. Mood and gradability: An investigation of the subjunctive mood in Spanish. Linguistics and Philosophy 31 (4): 467-522.

Werner, T. 2003. Deducing the future and distinguishing the past: Temporal interpretation in modal sentences in English. PhD thesis, Rutgers University.

Williamson, T. 2000. Knowledge and its limits. Oxford: Oxford University Press.

Yalcin, S. 2007. Epistemic modals. Mind 116: 983-1026.

Zanuttini, R., M. Pak, and P. Portner. 2012. A syntactic analysis of interpretive restrictions on imperative, promissive, and exhortative subjects. Natural Language and Linguistic Theory 30 (4): 1231-1274. 